\title{
Life performance of oil and gas platforms: Site integration and thermodynamic evaluation
}

\author{
Nguyen, Tuong-Van; Fülöp, Tamás Gábor; Breuhaus, Peter; Elmegaard, Brian
}

\author{
Published in: \\ Energy
}

Link to article, DOI:

10.1016/j.energy.2014.06.021

Publication date:

2014

Document Version

Early version, also known as pre-print

Link back to DTU Orbit

Citation (APA):

Nguyen, T-V., Fülöp, T. G., Breuhaus, P., \& Elmegaard, B. (2014). Life performance of oil and gas platforms:

Site integration and thermodynamic evaluation. Energy, 73, 282-301.

https://doi.org/10.1016/j.energy.2014.06.021

\section{General rights}

Copyright and moral rights for the publications made accessible in the public portal are retained by the authors and/or other copyright owners and it is a condition of accessing publications that users recognise and abide by the legal requirements associated with these rights.

- Users may download and print one copy of any publication from the public portal for the purpose of private study or research.

- You may not further distribute the material or use it for any profit-making activity or commercial gain

- You may freely distribute the URL identifying the publication in the public portal 


\title{
Life performance of oil and gas platforms: Site integration and thermodynamic evaluation
}

\author{
Tuong-Van Nguyen ${ }^{\mathrm{a}, *}$, Tamás Gábor Fülöp ${ }^{\mathrm{a}}$, Peter Breuhaus ${ }^{\mathrm{b}}$, Brian Elmegaard $^{\mathrm{a}}$ \\ ${ }^{a}$ Section of Thermal Energy, Department of Mechanical Engineering, Technical University of Denmark, \\ Building 403, Nils Koppels Allé, 2800 Kongens Lyngby, Denmark \\ ${ }^{b}$ Department of Energy, International Research Institute of Stavanger, \\ Professor Olav Hanssens vei 15, 4021 Stavanger, Norway
}

\begin{abstract}
Oil and gas platforms are energy-intensive systems, which operate under changing boundary conditions over time. In this paper, the life performance of an offshore platform is analysed by comparing three representative stages of an oil field (early-life, plateau and end-life productions). The energy requirements are assessed by a process integration study, and the system inefficiencies are pinpointed by performing an exergy accounting. The heating and cooling requirements vary significantly over time, and most inefficiencies take place in processes where chemical exergy is consumed $(\simeq 50-55 \%)$, thermal exergy is transferred $(\simeq 15-$ $20 \%)$, or mechanical exergy is varied $(\simeq 10-15 \%)$. These findings are valid for all production periods: this suggests that more attention should be paid on a proper integration of the processing and utility plants, by, for instance, recovering heat from the turbine exhausts and from the exported gas. Multi-objective optimisations are conducted for evaluating the integration of steam and organic Rankine cycles, considering thermodynamic, economic and environmental performance indicators. They indicate that the profitability of a given improvement measure mainly depends on (i) the field properties, (ii) the platform operating strategy, and (iii) the production stage of the oil field. The implementation of steam networks appears promising, as it results in a better performance of the offshore platform and in larger economic profits.
\end{abstract}

Keywords: Site integration, Exergy analysis, Oil and gas platform, Energy efficiency, Pinch technology

\section{Introduction}

The offshore processing of oil and gas is an energy-intensive sector, and each facility consumes from a few MW to several hundred MW of power. The petroleum extraction sector is responsible for about $25 \%$ of the total $\mathrm{CO}_{2}$-emissions of Norway [1], which result from the combustion of natural gas for local power generation. The Norwegian government levied a carbon tax on hydrocarbon fuels in 1991 to encourage reductions of the greenhouse gas emissions, and this tax was doubled to NOK $410(\$ 67)$ per ton of $\mathrm{CO}_{2}$ in $2012[2,3]$. In this context, there has been an increasing interest for promoting energy efficiency measures, by, for instance, integrating waste heat recovery cycles and electrifying platforms, i.e. by connecting these facilities to the onshore power grid.

However, the processing units on offshore platforms are designed for handling the peak production rates of oil and gas, which implies that they are operated far from their nominal design conditions at the startand end-life of the oil field. They suffer from (i) the variations in the production rates (e.g. GOR (gas-to-oil) and WOR (water-to-oil) ratios), (ii) the changes in the field conditions (e.g. well pressure), and (iii) the component degradation due to ageing (e.g. fouling). These events in the field life drive the power, heating and cooling demands of the oil and gas production plant. Energy management procedures should then

\footnotetext{
*Principal corresponding author. Tel.: +4545254129

Email addresses: tungu@mek.dtu.dk (Tuong-Van Nguyen), gab8630@gmail.com (Tamás Gábor Fülöp)
} 


\begin{tabular}{|c|c|c|c|}
\hline \multicolumn{4}{|c|}{ Nomenclature } \\
\hline$\dot{E}$ & Exergy rate, $\mathrm{W}$ & $\delta$ & relative variation \\
\hline$\dot{W}$ & Power, W & $\eta$ & energy efficiency \\
\hline $\mathrm{C}$ & Cost, $\$$ & $\varepsilon$ & exergy efficiency \\
\hline $\mathrm{T}$ & Temperature, $\mathrm{K}$ or ${ }^{\circ} \mathrm{C}$ & \multicolumn{2}{|c|}{ Superscripts } \\
\hline $\mathrm{e}$ & Specific exergy, $\mathrm{J} / \mathrm{kg}$ & * & relative \\
\hline $\mathrm{p}$ & Pressure, $\mathrm{Pa}$ & $\mathrm{ch}$ & chemical \\
\hline $\mathrm{y}$ & Exergy ratio, \% & $\mathrm{ph}$ & physical \\
\hline \multicolumn{2}{|c|}{ Abbreviations } & Q & heat \\
\hline $\mathrm{BCC}$ & Balanced Composite Curves & $\mathrm{W}$ & work \\
\hline $\mathrm{CC}$ & Composite Curves & \multicolumn{2}{|c|}{ Subscripts } \\
\hline DNA & Dynamic Networks Analysis & $j$ & stream \\
\hline EOS & Equation of State & $k$ & component \\
\hline GCC & Grand Composite Curve & 0 & dead state \\
\hline GOR & Gas-to-oil ratio & air & combustion air \\
\hline HRSG & Heat Recovery Steam Generator & cool & cooling \\
\hline ICC & Integrated Composite Curves & & ling wotor \\
\hline MINLP & Mixed Integer Non-Linear Programming & $\mathrm{cw}$ & cooling water \\
\hline NG & Natural Gas & $\mathrm{d}$ & destruction \\
\hline ORC & Organic Rankine Cycle & eg & exhaust gases \\
\hline $\mathrm{PP}$ & Processing Plant & $\mathrm{f}$ & fuel \\
\hline PR & Peng-Robinson & feed & feed \\
\hline $\mathrm{SRC}$ & Steam Rankine Cycle & fg & fuel gas \\
\hline SRK & Soave-Redlich-Kwong & heat & heating \\
\hline TSA & Total Site Analysis & hyp & hypothetical \\
\hline TSP & Total Site Profile & inv & investment \\
\hline UT & Utility Plant & iw & injected water \\
\hline WOR & Water-to-oil ratio & 1 & loss \\
\hline \multicolumn{2}{|c|}{ Greek letters } & $\mathrm{p}$ & product \\
\hline$\Delta$ & absolute variation & rw & rejected water \\
\hline
\end{tabular}

build on the forecasting of these changing energy requirements, while taking into account design constraints such as the oil export pressure. These variations were discussed in the works of Kloster $[4,5]$, Svalheim and King [6], as well as in Vanner [7].

The present paper investigates the applicability and findings of pinch-and exergy-based methods for assessing the life efficiency of such systems. Pinch-based methods are promising tools used to optimise the efficiency of industrial processes by energy integration. They were developed at first by Linnhoff [8], and the main focus is on targeting the heat integration potential in the system under study. These methods are suitable for designing new processes (grass-root) [9] or for improving existing ones (retrofit) [10]. They have also been extended from the analysis of an individual process to the assessment of a total site [11-14]. 
The energy saving opportunities are assessed at the site-scale, rather than at the level of a single process. The opportunities for inter-process integration, through a common utility system, can be identified, and an appropriate integration strategy can be selected. A detailed description of the TSA (Total Site Analysis) method is presented in Klemeš et al. [15].

The application of these methods to existing plants has grown recently. Feng et al. [16] investigated possible retrofit schemes for heat exchanger networks of petrochemical plants and pinpointed the importance of choosing the relevant boundaries (process or site). Matsuda et al. [17] applied the total site approach to a large-scale steel plant, which revealed the significant energy saving potential of the facility, despite that high efficiency of each individual process. Hackl et al. [18,19], following the same method, pinpointed the numerous opportunities for energy recovery in an industrial cluster, by allowing for closer collaboration between the chemical companies on-site, and implementing a hot-water circuit.

Exergy-based methods are well-established methods, which allow for assessing the locations and extents of the system imperfections [20]. Unlike energy, exergy is destroyed to a certain extent in real processes, and the quantity of exergy destroyed throughout successive process operations accounts for the performance losses of the system of interest, and thus for the additional fuel use [21,22]. A few studies on the performance of oil and gas plants, using the exergy analysis method, can be found in the scientific literature.

An exergy analysis was conducted on a generic offshore platform [23], considering six different feeds. The combustion reactions in the gas turbines were pointed out as the most exergy-destroying processes, and it was argued that few improvements on these components could be performed. The subsequent studies focused on improving the processing plant, following the work of Oliveira and Van Hombeeck [24] on a Brazilian facility. Four processing plants, located in the North Sea [25] and in the Norwegian Sea [26], were investigated. The sources of exergy destruction and losses were analysed. The findings illustrated that most irreversibilities were taking place either in the production manifold or gas compression sections, depending on the platform design, the exploitation period, and the reservoir conditions. The main causes were identified as the heat exchanges over large temperature gaps in the heaters and coolers, and the pressure changes in throttling valves and compressors. The challenges that are faced for improving these systems were pinpointed, because of the large changes in the oil and gas rates during the lifetime of the field.

In summary, the literature appears to contain little, if none, (i) on the application of advanced thermodynamic methods to assess the performance of oil and gas platforms, (ii) on the mapping of their performance losses over their life cycle, (iii) on the variations in heating and cooling demands of such processes, and (iv) on the systematic evaluation of improvement measures. The present study aims to help addressing these gaps, by combining the strengths of the pinch- and exergy-based methods. A Norwegian Sea offshore platform is taken as case study, and the model of this facility was explained in further details in Nguyen et al. [26]. The basic structural layout of this platform is similar to other offshore platforms exploiting oil fields in the North Sea [2].

The present work was structured following those four steps:

- the platform model was developed and calibrated, based on measured data and on engineering assumptions, for three different exploitation periods (early-life, plateau and end-life productions);

- the energy and exergy consumption trends and changes were evaluated;

- the sources and extents of the performance losses were assessed;

- different system integration alternatives were simulated and analysed.

The methods of analysis are described along with the system models in Section 2. Section 3 reports the results obtained, which are discussed in Section 4. Concluding remarks are outlined in Section 5. 


\section{Methodology}

\subsection{System description and modelling}

\subsubsection{Case study}

The platform investigated in this study exploits an oil field in the Norwegian Continental Shelf region, approaching its end-life phase. In the last decade, the oil and gas production has declined, while the water production has increased, resulting in a feed water cut, on a molar basis, over 85-90\% for most wells (Figure 1).

Petroleum and subsurface water enter the platform system through the production manifolds, in which the streams from the several wells are de-pressurised and mixed. Oil, gas and water are then dissociated by gravity in two separation stages operating at different pressure and temperature conditions. The recovered gas is first re-compressed to the initial feed pressure, and compressed further after purification of the water residuals and medium-weight hydrocarbons. Most high-pressure dry gas leaving the final compression stage is used for gas lift, i.e. introduced at the bottom of the oil wells to ease the reservoir fluid lift and maximise the liquid throughout. The remaining gas is partly exported to the coast and partly consumed in gas turbines for local power generation. The crude oil is stored and exported to the shore, while the produced water is treated and discharged into the sea.

The power generation is ensured by five gas turbines installed on-site: three are used to cover the power requirements of the processing units such as gas treatment and oil loading; the other two are dedicated to the water injection pumps only. The heating demand is satisfied by waste heat recovery from the turbine exhausts, internal heat recovery and electric heating. The cooling demand is met by processing seawater lifted on-site: all process coolers are run in parallel, and the cooling water flows are then mixed before rejection to the sea and/or injection into the reservoir.

In the rest of this study, the term processing plant refers to the oil and gas processing, which includes, among others, the production manifolds, the separation and the seawater injection processes. The term utility plant refers exclusively to the gas turbines, the waste heat recovery and the cooling water modules.

\subsubsection{System modelling and simulation}

Modelling basis. The offshore platform was simulated using Aspen HYSYS ${ }^{\circledR}$ [27]. The PR (Peng-Robinson) EOS (equation of state) [28] and the Twu-Coon-Cunningham EOS [29] were used for calculating the stream physical, chemical and thermodynamic properties. Since the exact oil composition is unknown, the heavy fractions are lumped and modelled as made-up components (hypothetical), based on crude oil assays and distillation curves [30]. The simulations were at first conducted on DNA (Dynamic Networks Analysis) [31], which is an in-house software developed at the Technical University of Denmark, and implemented on Aspen HYSYS ${ }^{\circledR}$ in a further step. More details on the system modelling can be found in Nguyen et al. [26].

For the power generation sub-system, the compressor off-design characteristics were derived by applying a stage-stacking analysis [32-34], while the calculations of the isentropic efficiency of each stage were based on the pressure drop assumptions presented in Templalexis et al. [35], and the works of Lieblein [36] and of Saravanamuttoo et al. [37]. The turbine off-design characteristics were derived following the method described in Stodola [38] and in Traupel [39].

For the equipment items used in the other sub-systems, the efficiencies of the pumps and compressors were derived from generic performance maps (see e.g. Ref. [40]) and they were then adjusted to fit with the measurements. The off-design behaviour of the heat exchangers was modelled using the logarithmic mean temperature difference method. The heat transfer coefficients were calculated based on the manufacturing component data-sheets, and the conductive thermal resistances were neglected.

Simulation cases. Three base simulation cases were considered in this study, each corresponding to a different stage in the lifespan of the oil field. They cover three representative production phases of an offshore platform (Figure 2). The first case corresponds to the early-life production: the oil rate increases, while the gas and water production are insignificant. Gas and condensate were re-injected into the reservoir through dedicated wells, as there were no pipelines for exporting them. The second case corresponds to a plateau case, where the oil rate has reached its maximum. Most equipments are designed for this point of time, and this case 


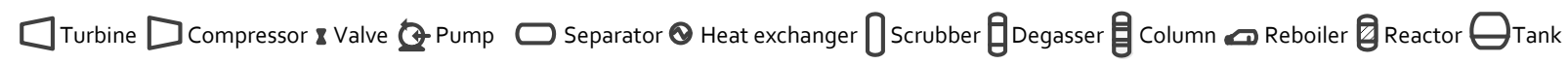

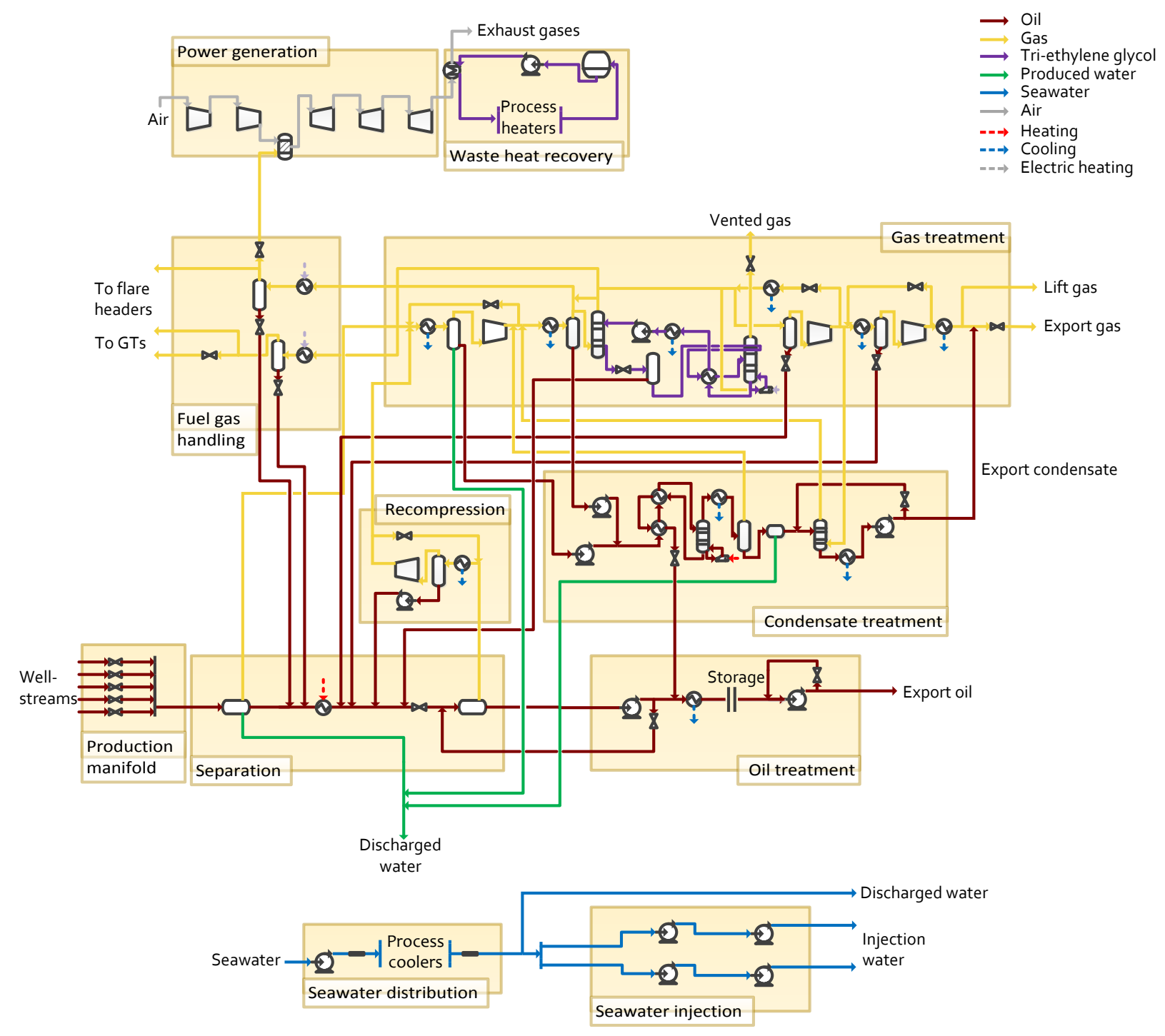

Figure 1: Process flow diagram of the Norwegian Sea offshore platform investigated in this work, based on input by Norske Shell A/S and data collected from the literature. For ease of reading, only the most significant recycling loops are drawn, and only one gas turbine is shown. The addition of chemicals such as glycol and methanol to prevent hydrate formation is not indicated, and redundant components that are run in parallel (e.g. pumps and separators) are merged into one. 
determines the maximum head and power requirements of the system. The third and final case corresponds to an end-life case, where the oil and gas productions have sharply decreased, and the water content of the feed is greater than $85 \%$, on a molar basis (Table 1 ).

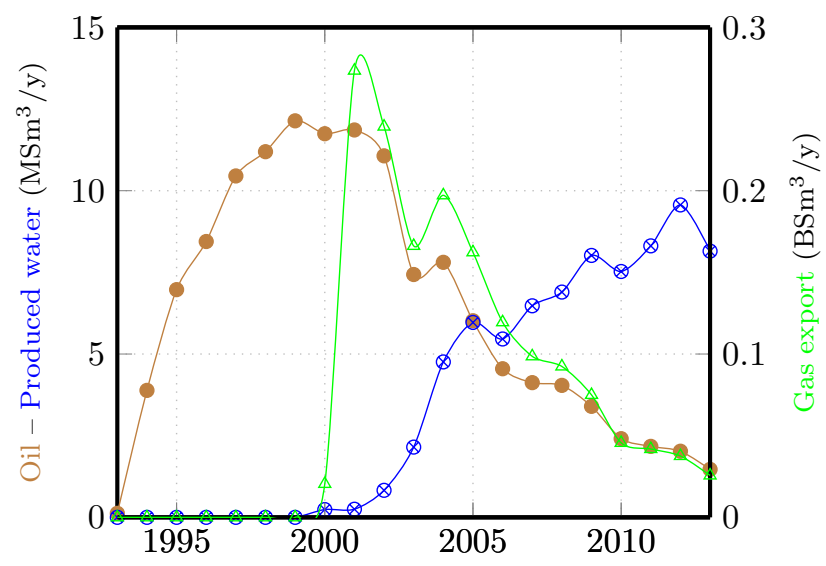

Figure 2: Oil, gas and water production and exports for the platform under study, from 1993 to 2013 [41].

In the early- and end-life situations, the flow rate of the gas extracted from the wells, and thus of the gas entering the recompression and treatment sections, is significantly lower than what the process was designed for. Gas is therefore recycled around the compressors to prevent surge, as a minimum flow rate through the compressors should be maintained. These three cases are set up to underline (i) the significant differences in operating conditions between each life cycle stage, and (ii) the variations of the heating and cooling demands over time, and (iii) the changes in the locations and extents of the system inefficiencies.

Table 1: Simulated flow rates of the process streams at the outlet of the offshore platform.

\begin{tabular}{lrrrr}
\hline & Variable & Start & Peak & End \\
\hline Exported oil & $\mathrm{F}, \mathrm{Sm}^{3} / \mathrm{h}$ & 948.1 & 1325.1 & 279.1 \\
Exported gas & $\mathrm{F}, 10^{3} \mathrm{Sm}^{3} / \mathrm{h}$ & $\simeq 0$ & 111.8 & 23.5 \\
Produced water & $\mathrm{F}, \mathrm{Sm}^{3} / \mathrm{h}$ & $\simeq 0$ & 31.6 & 1128.5 \\
\hline
\end{tabular}

\subsection{Process and energy integration}

\subsubsection{Pinch technology}

For a thorough introduction to the pinch analysis method, the reader is referred to the textbooks of Linnhoff and Boland [42], Kemp [43] and Klemeš et al. [15]. The main steps can be summarised as:

- extraction of the appropriate stream data (temperatures, pressures, flow rates);

- choice of individual temperature differences $\left(\frac{\Delta T_{\min }}{2}\right)$ and calculating the energy targets;

- investigation of the possible process changes that could result in a higher energy performance;

- design of a new heat exchanger network (grass-root) or analysing an existing one (retrofit);

- optimisation of the energy (operating) costs against capital ones.

This method lies on the use of temperature-enthalpy curves to illustrate the energy demands of each process or system, such as the CC (Composite Curves) and GCC (Grand Composite Curve). Alternatively, 
the integration of the utilities with the main processes can be investigated with the BCC (Balanced Composite Curves) [43]: these curves are modified composite curves, in which the utility streams are included. Finally, the integration of a given sub-system in relation to the whole site can be visualised with the ICC (Integrated Composite Curves) [44]: these curves also derive from the composite curves, dividing the site into two sub-systems, the first one includes the process one wants to focus on, whilst the second one includes the remaining processes. The individual temperature differences $\left(\Delta T_{\min } / 2\right)$ are taken as 2,4 and $8^{\circ} \mathrm{C}$ for phase-changing, liquid and gaseous streams.

\subsubsection{Total site integration}

The TSA method $[11,14]$ builds on the pinch analysis: this methodology is extended to a total site plant, which consists of several processes with their own utility systems, internal or external, and possibly linked by a common and central utility plant. The individual heating and cooling demands of each process are evaluated: the GCC of each process are constructed and combined into single source and sink profiles, giving therefore an overview of the heat surplus and deficit of the total site. These curves are named the TSP (Total Site Profiles) and illustrate the opportunities for heat recovery at the level of the total site, as well as the use of the several local utilities (e.g. cooling water and electric heating). This method aims thus at improving the efficiency of the overall site by promoting flow and energy interactions between the different processes. The overall procedure is similar to that for a conventional pinch analysis, with the difference that it is repeated for each individual process.

Different levels of details can be chosen when extracting the stream data and evaluating the heat integration of the system under study. The first level is called the white-box approach: all the heat requirements of the process streams are considered with their appropriate temperature levels. The second level is named the grey-box approach: the heat exchanges between two process streams are ignored, meaning that the selfsufficient pockets of the grand composite curves are excluded. The third and last level is called the black-box approach: the temperatures at which energy is required are unknown, and the energy requirements are represented by the temperature levels of the utility streams (e.g. cooling water and exhaust gases).

Pinch analysis studies generally build on the white-box approach, while total site studies lie on the greybox framework. The latter assumes that the heat exchanges taking place between two process streams are accepted as they are, and that they are excluded from the process integration study. The total site analyses deal only with the integration between different processes and do not deal with the improvement of the heat integration within each single process. However, in this work, the possibility to use the energy within the self-sufficient pockets is considered, as it could be used for cogeneration purposes [45-47].

Several scenarios can be considered, depending on whether there are heat exchange restrictions between streams belonging to different sub-systems of an offshore platform. The case without any heat exchange restriction defines an ideal target for improving the system, which cannot be exceeded. On the contrary, the case where no heat recovery is possible defines the maximum demand for the use of utilities.

\subsection{Exergy analysis}

\subsubsection{Exergetic accounting}

For a thorough introduction to the exergy analysis method, the reader is referred to the textbooks of Szargut [48], Kotas [49], or Moran and Shapiro [50]. As a recall, exergy may be defined as the maximum theoretical useful work as the system is brought into complete thermodynamic equilibrium with the thermodynamic environment while the system interacts with this environment only [51-53]. Unlike energy, exergy is not conserved in real processes - a fraction is destroyed due to the system internal irreversibilities, which are called in the rest of this work exergy destruction $\left(\dot{E}_{\mathrm{d}}\right)$. The exergy discharged to the environment, without any practical use, such as the thermal exergy losses with the turbine exhausts, is denoted exergy losses $\left(\dot{E}_{1}\right)$. The exergy balance for the complete platform can be expressed as: 


$$
\begin{aligned}
& \dot{E}_{\mathrm{feed}}+\dot{E}_{\mathrm{air}}+\dot{E}_{\mathrm{cw}}=\sum_{j} \dot{E}_{j}+\dot{E}_{\mathrm{rw}}+\dot{E}_{\mathrm{eg}}+\dot{E}_{\mathrm{iw}}+\dot{E}_{\mathrm{d}, \mathrm{PP}}+\dot{E}_{\mathrm{d}, \mathrm{UT}} \\
& \dot{E}_{\mathrm{feed}}+\dot{E}_{\mathrm{UT}}^{W}+\dot{E}_{\mathrm{UT}, \text { heat }}^{Q}=\sum_{j} \dot{E}_{j}+\dot{E}_{\mathrm{fg}}+\dot{E}_{\mathrm{PP}, \mathrm{cool}}^{Q}+\dot{E}_{\mathrm{d}, \mathrm{PP}} \\
& \dot{E}_{\mathrm{fg}}+\dot{E}_{\mathrm{air}}+\dot{E}_{\mathrm{cw}}+\dot{E}_{\mathrm{PP}, \mathrm{cool}}^{Q}=\dot{E}_{\mathrm{rw}}+\dot{E}_{\mathrm{eg}}+\dot{E}_{\mathrm{iw}}+\dot{E}_{\mathrm{UT}}^{W}+\dot{E}_{\mathrm{UT}, \text { heat }}^{Q}+\dot{E}_{\mathrm{d}, \mathrm{UT}}
\end{aligned}
$$

For the first equation, the left-hand side term represents, on a time rate basis, the exergy associated with the feed entering the processing plant (i.e. reservoir fluid) $\dot{E}_{\text {feed }}$, with the air sent to the gas turbines $\dot{E}_{\text {air }}$, and the seawater used for cooling purposes $\dot{E}_{\mathrm{cw}}$. The right-hand side term denotes the exergy of the outlet streams of the processing plant (i.e. oil, gas, condensate, flared gas, produced water, but not fuel gas) $\sum_{k} \dot{E}_{k}$ and the exergy discharged to the environment with the cooling water $\dot{E}_{\mathrm{rw}}$, the exhaust gases $\dot{E}_{\text {eg }}$, and the injected water $\dot{E}_{\mathrm{iw}}$. $\dot{E}_{\mathrm{d}, \mathrm{PP}}$ is the exergy destroyed in the processing plant and $\dot{E}_{\mathrm{d}, \mathrm{UT}}$ the exergy destroyed in the utility plant.

The second and third equations correspond to the exergy balances for the processing and utility plants, where $\dot{E}_{\mathrm{fg}}$ stands for the exergy associated with the fuel gas extracted in the processing plant, and consumed in the gas turbines, $\dot{E}_{\mathrm{UT}}^{W}$ for the exergy transferred with power, $\dot{E}_{\mathrm{UT} \text {,heat }}^{Q}$ for the heat exergy recovered from the waste heat recovery sub-system, and $\dot{E}_{\mathrm{PP} \text {,cool }}^{Q}$ for the exergy discharged to the cooling water from the oil and gas streams.

In this work, the potential and kinetic effects are neglected, and the exergy associated with a material stream is a function of its physical $e^{\mathrm{ph}}$ and chemical $e^{\mathrm{ch}}$ parts only. The dead state is taken at $8^{\circ} \mathrm{C}$ and 1.013 bar, as these are the average air conditions in the North Sea [54]. The chemical exergy of real chemical compounds is calculated based on the concept of standard chemical exergy, using the reference environment defined by Szargut $[48,55,56]$. The chemical exergy of hypothetical components $e_{\text {hyp }}^{\text {ch }}$ is computed with the heuristic correlations of Rivero [57].

\subsubsection{Exergetic indicators}

Several exergy-based performance indicators can illustrate the possibilities for improvement and indicate the components and sub-systems on which attention should be focused:

- the exergy destruction ratio, $y_{\mathrm{d}}^{*}$, defined as the ratio of the exergy destruction rate within a specific process component $k$, to the exergy destruction of the whole system $\dot{E}_{\mathrm{d}}$;

- the exergy losses ratio, $y_{1}^{*}$, defined as the ratio of the exergy loss rate associated with a given waste stream $j$, to the exergy losses of the whole system $\dot{E}_{1, j}$.

- the exergetic efficiency $\varepsilon$ of a given component $k$ or sub-system, which reflects its thermodynamic performance: the formulations of exergetic efficiencies for the components investigated within this study are presented in Bejan et al. [51] and in Kotas [22,49,58].

\subsection{Multi-objective optimisation}

\subsubsection{Performance indicators}

Several improvement measures can be suggested, based on the outcomes of the total site and exergy analyses. They can be evaluated by using thermodynamic, economic and environmental performance indicators, such as:

- the net power capacity $\dot{W}$;

Two approaches could be applied. The first one is to consider that an objective is to maximise the net power capacity, which is appropriate (i) if the power demand is expected to increase, for instance if new wells are drilled, or if larger amounts of water are injected to increase the oil recovery; (ii) if 
power can be exported to a nearby platform or ashore; or (iii) if the steam network can be used to replace and remove a gas turbine from the facility.

The second one is to assume that the power demand is set by the process requirements and is nearly constant. In this case, the improvement measures would focus on minimising the fuel gas consumption and the possible investment costs. The first approach is preferred in this work, as power sharing between different installations and platform electrification is currently a topic of high relevance.

- the energy $\eta$ and exergy efficiencies $\varepsilon$;

- the additional grass-root costs $C_{\mathrm{inv}}$, which are associated with the installation of new equipments;

The grass-root costs are calculated based on the correlations of Turton et al. [59], which are claimed to have an uncertainty of $\pm 30 \%$, and based on the process operating conditions (e.g. flows, temperatures and pressures).

- the increase of NG (natural gas) export $\delta_{\mathrm{NG}}$, if less power is required;

- the decrease of the $\mathrm{CO}_{2}$-emissions $\delta_{\mathrm{CO}_{2}}$, if less carbon dioxide is produced;

- the $\mathrm{CO}_{2}$-avoidance cost, defined as the ratio of the additional costs to the reduction of the $\mathrm{CO}_{2}$ emissions.

The issues of risk failure and availability are out of the scope of this study.

\subsubsection{Problem formulation}

Decision-makers should carefully evaluate the trade-off between thermodynamic, economic and environmental aspects when integrating new processes. For instance, integrating a steam cycle results in additional investment costs, but smaller $\mathrm{CO}_{2}$-emissions and higher natural gas export. This problem can be formulated as an optimisation problem, considering three conflicting objective functions: minimum investment costs, minimum local $\mathrm{CO}_{2}$-emissions and maximum net power capacity.

The decision variables of the optimisation problem, i.e. the variables within the model that the decisionmaker controls, are related to design and operational parameters (Table 2). Some of these variables are continuous, i.e. they may take on any value between a lower and upper bound, whilst the others are discrete, i.e. they may take on only some specific values, such as 0 or 1 . An example of a continuous variable is the pressure level at which the steam production in a steam cycle takes place, which is varied, in this work, between 5 and 25 bar. On the other hand, an example of a discrete variable is the selection of the cooling source for the steam condenser: either the cooling water from the processing plant is selected, or additional water from the sea is pumped and lifted. The starting assumptions are taken from Maréchal and Kalitventzeff [60] for the SRC (steam Rankine cycles) and from Rohde et al. [61] for the low-temperature ORC (organic Rankine cycles).

The multi-objective optimisation problem is therefore a MINLP (Mixed Integer Non-Linear Programming) problem, which is solved by using a genetic algorithm [62,63] and by displaying the solutions as a Pareto optimal frontier [64]. This front illustrates that any better-off with respect to a particular objective results in a worse-off with respect to another one. All the possible process and system configurations are embedded in the superstructure and considered in the optimisation problem.

The multi-objective optimisations are first conducted considering that there are no heat exchange restrictions, and the obtained solutions are therefore ideal targets, which can serve as benchmarks. They are run, in a second step, considering that process streams belonging to different sub-systems cannot directly exchange heat together. In such cases, the heating and cooling demands are satisfied by internal heat recovery within the sub-system of interest and by the use of external utilities. 
Table 2: Set of the master decision variables used in the multi-objective optimisation routines.

\begin{tabular}{|c|c|c|c|}
\hline Variable & Type & Unit & Range/Value \\
\hline Production level & continuous & bar & {$[9-25]$} \\
\hline Degree of superheating & continuous & $\mathrm{K}$ & {$[0-100]$} \\
\hline Selection of reheating & integer & - & $\{0 ; 1\}$ \\
\hline Reheating level & continuous & $\mathrm{K}$ & {$[300-523]$} \\
\hline Selection of 2 nd production level & integer & - & $\{0 ; 1\}$ \\
\hline 2nd production level & continuous & bar & {$[90-130]$} \\
\hline Selection of extraction level & integer & - & $\{0 ; 1\}$ \\
\hline Extraction level & continuous & $\mathrm{K}$ & {$[300-523]$} \\
\hline Condensation level & continuous & $\mathrm{K}$ & {$[298-343]$} \\
\hline Vapour fraction (turbine outlet) & continuous & - & {$[0.8-1]$} \\
\hline Selection of seawater & integer & - & $\{0 ; 1\}$ \\
\hline Selection of processed cooling water & integer & - & $\{0 ; 1\}$ \\
\hline Selection of produced water & integer & - & $\{0 ; 1\}$ \\
\hline Selection of thermal intermediate loop & integer & - & $\{0 ; 1\}$ \\
\hline \multirow[t]{3}{*}{ Rejection temperature } & continuous & $\mathrm{K}$ & [281-318] (seawater) \\
\hline & continuous & $\mathrm{K}$ & [288-318] (processed cooling water) \\
\hline & continuous & $\mathrm{K}$ & [338-368] (produced water) \\
\hline Use of exhaust gases from the 2 nd GT & integer & - & $\{0 ; 1\}$ \\
\hline Exhaust temperature (after SRC) & continuous & $\mathrm{K}$ & {$[393-453]$} \\
\hline Gas turbine load for the SRC design point & continuous & $\%$ & {$[40-100]$} \\
\hline Power share between the $\mathrm{CC}$ and the $2 \mathrm{nd} \mathrm{GT}$ & continuous & $\%$ & {$[50-90]$} \\
\hline Selection of the low-temperature ORC & integer & - & $\{0 ; 1\}$ \\
\hline Selection of the working fluid & discrete & - & $\{0 ; 1 ; 2 ; 3\}$ \\
\hline Production level & continuous & bar & {$[10-80]$} \\
\hline Condensation level & continuous & bar & {$[10-80]$} \\
\hline Degree of superheating & continuous & $\mathrm{K}$ & {$[0-100]$} \\
\hline Ethane weight fraction & continuous & $\%$ & {$[0-100]$} \\
\hline
\end{tabular}




\section{Results}

\subsection{Total site integration}

\subsubsection{Assessment of the energy requirements}

The total heating demand of the site varies between 5 and $21 \mathrm{MW}$, and can be categorised as follows:

- the largest heating demand (between 2 and $15 \mathrm{MW}$ ) is identified as the crude oil heating in the separation process. A fraction of the oil from the 1 st separation stage, at $45-55^{\circ} \mathrm{C}$, is heated to $80-90{ }^{\circ} \mathrm{C}$ before entering the 2 nd separation stage. The fluid viscosity decreases and the vapour fraction increases to $2-5 \%$. It is then mixed to the oil fraction that has by-passed the heater, and the temperature after mixing is about $70-80^{\circ} \mathrm{C}$. The separation between the gas and oil phases is enhanced, and this prevents a too high vapour pressure of the oil;

- the second largest heating demand (between 1 and $4 \mathrm{MW}$ ) is found at the reboiler of the condensate stripping column. The condensate recovered from the gas cooling contains both light- and mediumweight hydrocarbons. The presence of light-hydrocarbons (e.g. methane) results in a more volatile product, and these chemical compounds should be reintroduced in a gaseous form in the gas processing section. On the contrary, the medium-weight hydrocarbons (e.g. iso-butane) should be mixed with oil and exported to the shore. The boiling-off of the light hydrocarbons from the condensate is called stabilisation, and takes place in the stripping column at temperatures of $180-200^{\circ} \mathrm{C}$.

- other heating demands amount to less than $300 \mathrm{~kW}$ each: glycol is used to dehydrate wet gas, and the glycol-water mixture should be heated in a column up to $205^{\circ} \mathrm{C}$ to regenerate and re-use the glycol back in the gas treatment section. The fuel gas entering the gas turbines should be heated from $40^{\circ} \mathrm{C}$ to about $65^{\circ} \mathrm{C}$.

The total cooling demand varies between 27 and $44 \mathrm{MW}$, and can be subdivided as follows:

- the gas cooling prior to the gas treatment section: the gas flows is cooled from temperatures between 70 and $140{ }^{\circ} \mathrm{C}$ to about 30 to $50^{\circ} \mathrm{C}$, in order to condense medium- and heavy-weight hydrocarbons, further removed in the scrubber, and to reduce the compression power;

- the oil cooling after separation: the mixed oil and condensate flow is cooled down to $25-30{ }^{\circ} \mathrm{C}$, to reduce the pumping power and ease further export.

The heating and cooling requirements are particularly sensitive to the oil rate, while they are moderately varying with the gas rate. The drop of the oil rate of about $80 \%$ between the peak and end-life productions has resulted in a reduction of $80 \%$ and $40 \%$ of the heating and cooling demands, respectively.

In a plateau situation, the large oil throughput results in significant heating in the separation and condensate stabilisation processes, and in high gas recovery. In start-and end-life situations, the compressed gas should be throttled and recycled to prevent surge of the turbomachinery components, implying that the gas rates into each cooler are nearly constant over time. The decrease in the cooling demand results from the lower cooling demand of the oil before further pumping and export.

A pinch analysis of each individual process illustrates that the gas recompression, the oil pumping, the fuel gas handling are processes where only either heating, or cooling, is required. Internal heat recovery is not feasible, and the energy demands should then be satisfied by using external utilities.

\subsubsection{Integration of the utility system}

The major heating demands (i.e. oil heating and condensate reboiling) are currently covered by waste heat recovery from the exhaust gases of three of the five gas turbines (Figure 3). An intermediate heating loop of triethylene glycol, heated up to $220^{\circ} \mathrm{C}$, operates in-between, flowing first through the condensate reboiler and then to the crude oil heater. The return temperature was controlled to vary between 120 and $140{ }^{\circ} \mathrm{C}$ when the oil production reached its peak, and currently varies between 180 and $200{ }^{\circ} \mathrm{C}$, as the need for heating has decreased. 
The remaining heating demands (i.e. fuel gas and glycol regeneration) are satisfied by electric heating and are nearly constant over time. Internal heat recovery on-site is minimal, and takes place between the condensates entering the stabilisation column and exiting the bottom reboiler. The cooling demand is mainly satisfied by processing seawater, rejected to the environment at temperatures of 15 to $35^{\circ} \mathrm{C}$.

The waste heat from the exhaust gases that is available at temperatures above the highest process temperature $\left(204.5^{\circ} \mathrm{C}\right.$ ) ranges between 18 and $21 \mathrm{MW}$. This represents between one (peak production) to six (end-life production) times the total site heating demand $\left(\dot{Q}_{\mathrm{H}}\right)$ and five (peak production) to six (endlife production) times the minimum external heating requirements $\left(\dot{Q}_{\mathrm{H}, \mathrm{min}}\right)$. The residual heat from the exhaust gases, i.e. the waste heat between the highest process temperature and the environmental conditions, ranges between 30 and $35 \mathrm{MW}$. The low-temperature waste heat discharged with the gas streams, available at temperatures below $150{ }^{\circ} \mathrm{C}$, represents about $70 \%$ of the residual waste heat from the exhaust gases on an energy basis, and about $60 \%$ on an exergy basis.

\subsubsection{Analysis of the site profiles}

The total site profiles illustrate the large gaps between the hot utility and the heat sink curves, and between the heat source and cold utility curves (Figure 4), suggesting that there is a large amount of exergy destroyed in the heat exchanger network. The pinch point of a given process or system is located at the point where the hot and cold composite curves are closest to each other. At all times, the pinch point corresponds to a temperature of $150-200^{\circ} \mathrm{C}$, which is the reboiling temperature in the condensate stabilisation column. The maximum heating $\left(\dot{Q}_{\mathrm{H}}\right)$ and cooling $\left(\dot{Q}_{\mathrm{C}}\right)$ demands amount to 21 and $44 \mathrm{MW}$, respectively. The grand composite curve of the system shows that the minimum demand for external heating $\left(\dot{Q}_{\mathrm{H}, \min }\right)$ is smaller than $5 \mathrm{MW}$, while the minimum demand for external cooling $\left(\dot{Q}_{\mathrm{C}, \min }\right)$ is smaller than $30 \mathrm{MW}$, if heat integration at the total site level can be performed. This corresponds to a maximum internal heat recovery of 10 to $15 \mathrm{MW}$ (Figure 5).

In practice, direct heat exchange between the process streams may not be feasible for operational reasons, and a combined utility system may be used. In this case, the potential for heat recovery is limited to less than 2 to $3 \mathrm{MW}$. The use of a central utility system is not beneficial from a process integration prospective, because:

- most heating demands take place at temperatures higher than the temperature of the cooling water utility system;

- most cooling demands take place at temperature lower than the temperature of the hot glycol utility system;

- two temperature differences should be considered: from the heat source (e.g. hot gas) to the utility stream (e.g. hot water), and from the utility stream to the heat sink (e.g. cold oil);

Improving the integration of the current system can only be performed by:

- allowing direct heat exchange between the process streams belonging to different sub-systems;

- improving the integration of the oil and gas processing system with its utilities, i.e. by using a hot utility at a lower temperature, or by using a cold utility at a higher one.

In the first case, the site profiles show that all the site cooling demand takes place at temperatures lower than $120^{\circ} \mathrm{C}$, and only the oil heating process takes place at this level of temperatures. This heat exchange faces two issues. First, all the gas streams should be cooled down to $20-50^{\circ} \mathrm{C}$, and the oil stream has an initial temperature of $45-55^{\circ} \mathrm{C}$. The gas streams should therefore be cooled in two steps, by first exchanging heat with the oil, and then with cooling water. Secondly, the oil stream cannot be heated by only one gas stream, as the heating demand for the oil can reach up to $12 \mathrm{MW}$, while the cooling demand for each individual gas stream does not exceed $4 \mathrm{MW}$. These temperature and enthalpy mismatches suggest that allowing for heat recovery between different sub-systems may result in a complex heat exchanger network. 

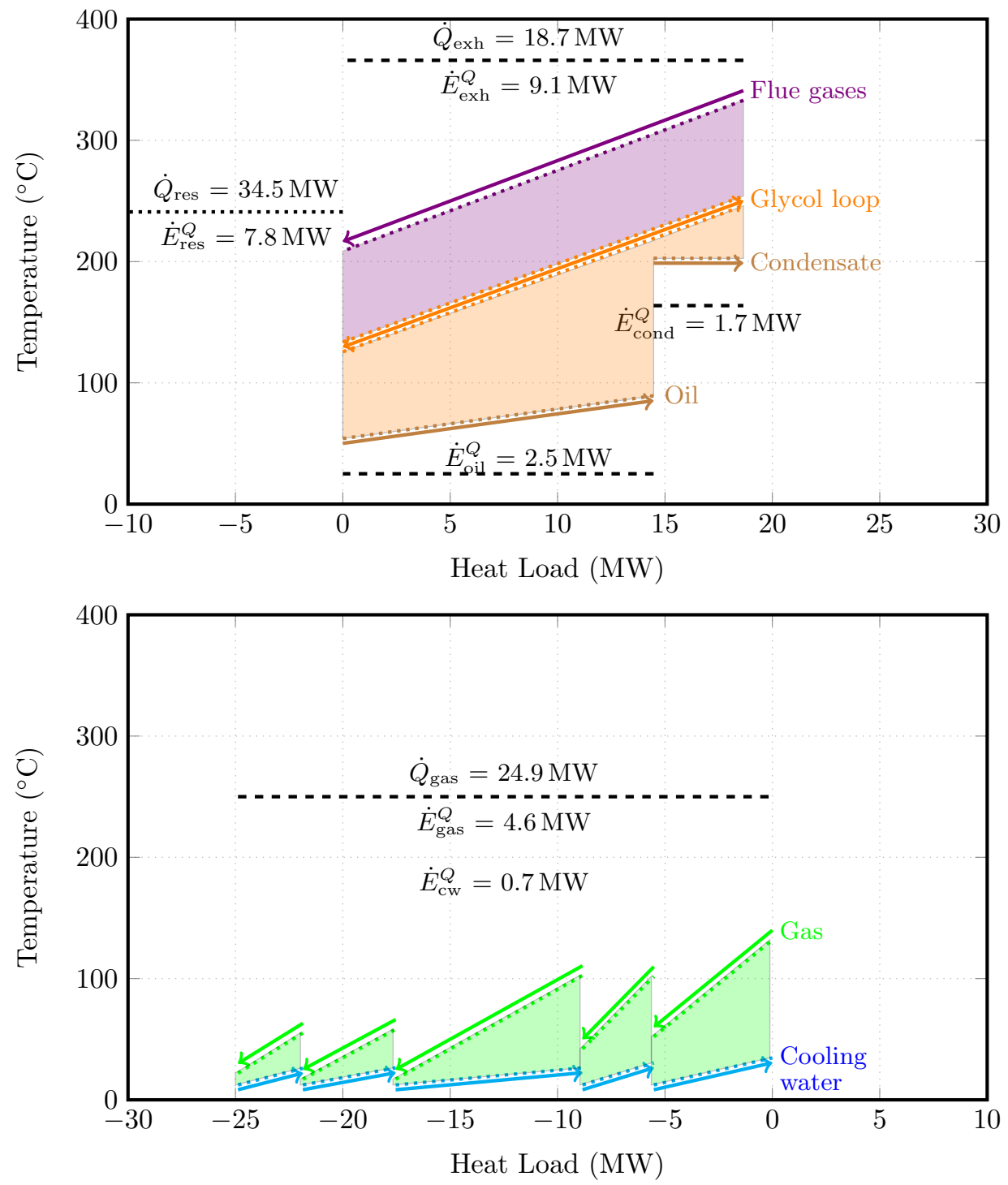

Figure 3: Temperature-enthalpy diagrams of the site heating (oil heating and condensate treatment) and cooling demands (gas recompression and treatment) for the peak production case. They are illustrated with the thermodynamic (process), technology (glycol loop) and utility (exhaust gases and cooling water) requirements. The full lines correspond to the real temperatures, the dotted lines to the corrected ones (i.e. adjusted with the individual temperature differences $\frac{\Delta T}{2}$ ), and the dashed ones to the energy demands. The shaded areas illustrate the exergy destruction in the successive heat exchanges. For more readability, all the residual heat is not shown in the figure. 

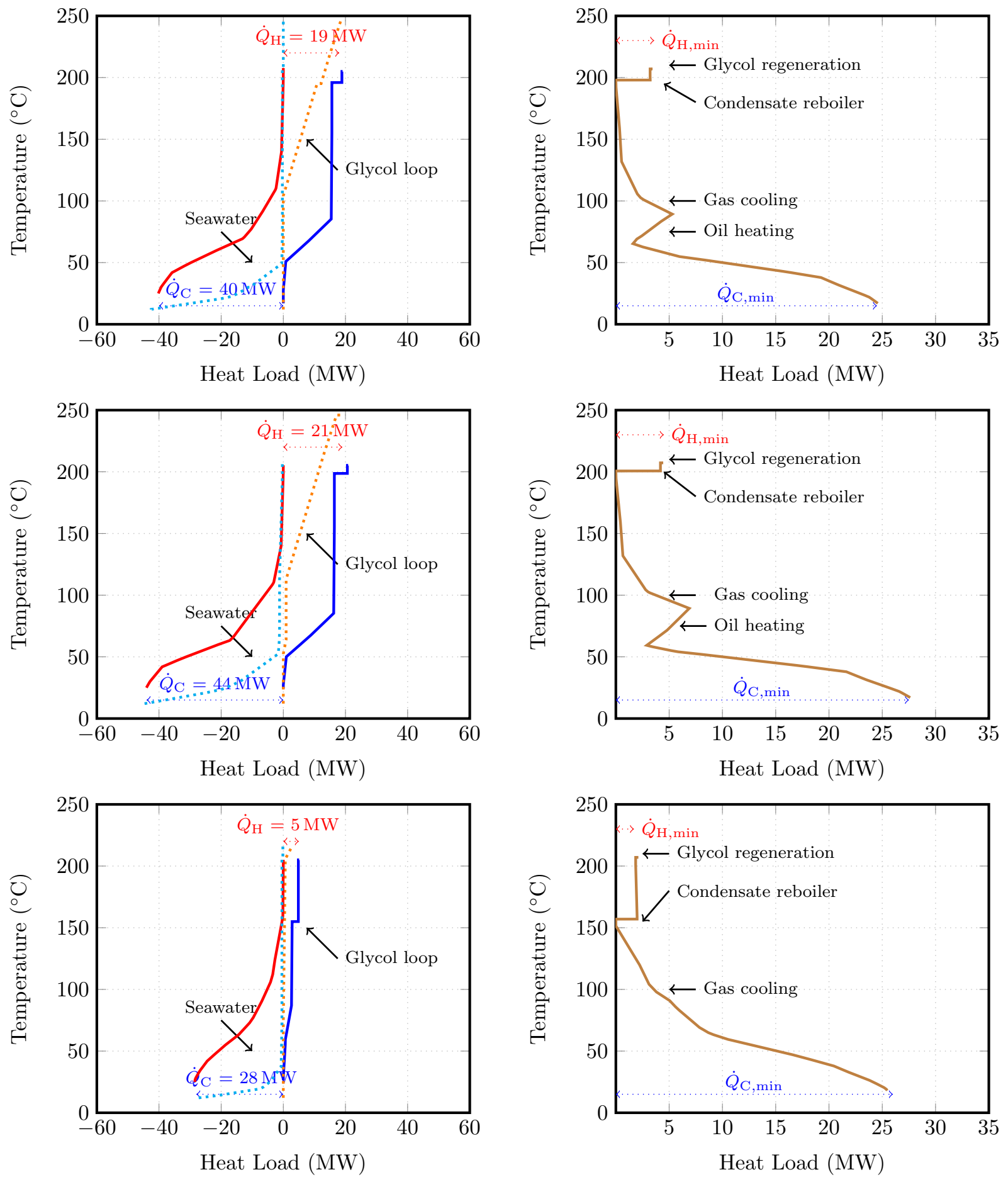

Figure 4: Total site profiles of the offshore plant with its current utility system (left) and grand composite curve of the process streams (right) for the start, plateau and end-life productions. The hot and cold process streams are represented by continuous lines, while the hot and cold utility streams are illustrated by dotted ones. 

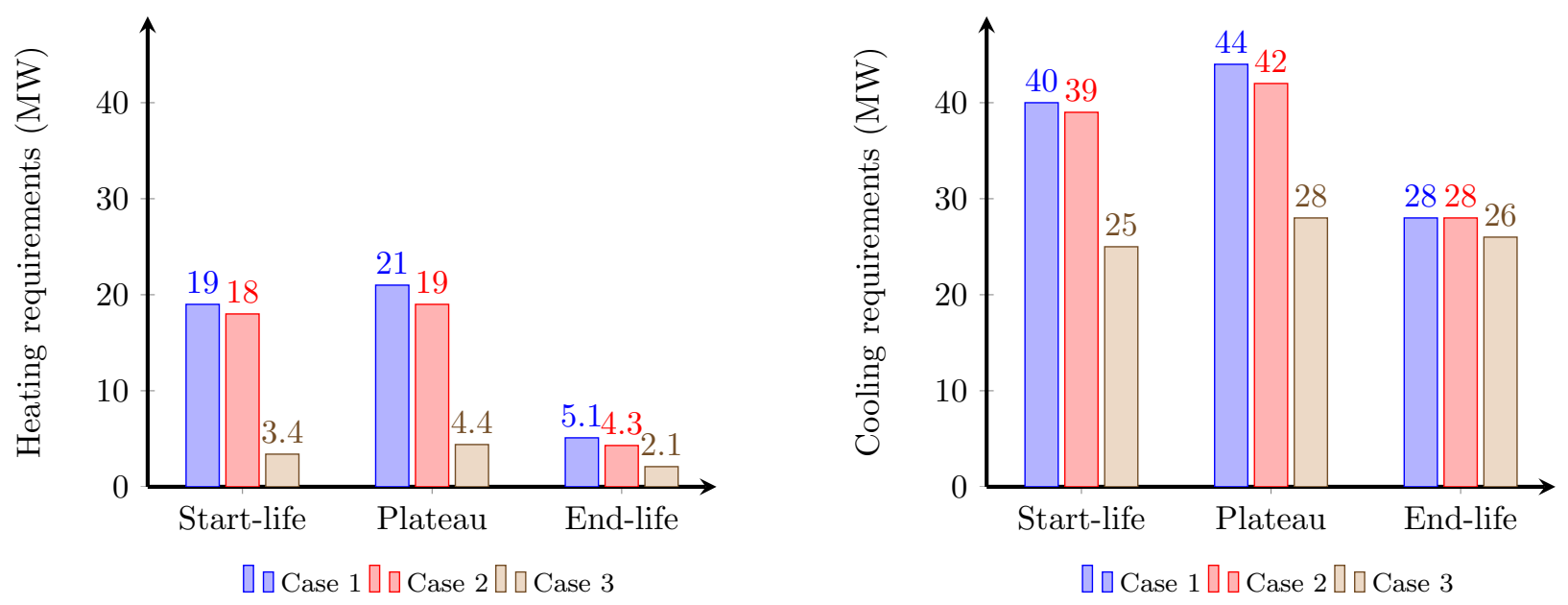

Figure 5: Energy requirements and savings without heat recovery (Case 1), with internal heat recovery within sub-systems (Case 2), and within total site (Case 3).

Another disadvantage is that such a highly integrated system may face reliability issues, and a fall-back solution should then be implemented to react to possible component failures. The rest of the present study focuses therefore on the second possibility, which is to improve the integration of the utilities within the oil and gas platform.

\subsection{Exergy analysis}

\subsubsection{Exergy flows}

The exergy analysis shows that exergy enters the oil and gas platform along with the hydrocarbons contained in the well-streams, as well as with the seawater and the chemicals imported for water treatment. Similarly, most exergy exits the facility with the oil exported to the shore and with the gas used for lifting the reservoir fluids. The largest contribution to the exergy inflows and outflows corresponds to the chemical exergy associated with the hydrocarbons: the latter are separated in the processing plant, and consumed, to a minor extent, as fuel gas in the gas turbines.

The results illustrate that, at all times, most exergy entering the offshore platform system transits without being converted or used, giving the misleading impression of a high thermodynamic performance. The hydrocarbon compounds are not consumed, except a small fraction in the combustion chambers of the gas turbines, and are simply separated in the separators and distillation columns.

The exergy entering the facility with the well-streams amounts to $10,700 \pm 270 \mathrm{MW}$ in the early-life, $14,900 \pm 370 \mathrm{MW}$ in the plateau, and $3800 \pm 100 \mathrm{MW}$ in the end-life cases. The exergy flowing with the air and cooling water are negligible in comparison, representing less than $50 \mathrm{MW}$ in total. Similarly, the exergy sent to the shore with the exported flows of hydrocarbons in the oil, gas and condensate amount to $9620 \pm 240 \mathrm{MW}, 14,100 \pm 350 \mathrm{MW}$ and $2940 \pm 70 \mathrm{MW}$ for the three investigated cases. About $700-900 \pm 20 \mathrm{MW}$ of exergy is used on-site for either power generation or gas lift.

The chemical exergy of the hydrocarbons compounds is calculated by using the PR EOS for the computation of the enthalpies and entropies and with correlations from the works of Rivero [65]. This inherent uncertainty of the EOS results in a spin of about 2 to $3 \%$, which may be higher in the case of oil and gas platforms processing heavy oils. The use of other EOS such as the RKS (Redlich-Kwong with Soave modifications) EOS results in differences of less than $1 \%$ for the prediction of the enthalpies and entropies and $2 \%$ for the standard volume flows. The greatest difference lies in the estimations of the oil actual volume flows, which is expected, as the RKS EOS fails in predicting accurately the density of liquid hydrocarbons.

The physical exergy of the well-streams represents less than $1 \%$ of the total flow exergy. For the streams that are mainly in liquid phase, especially in the end-life case, it is dominated by its temperature-based 
(thermal) part. The same conclusion can be drawn for the oil and produced water streams. On the other hand, the physical exergy of the well-streams that mostly contain gas, is dominated by its pressure-based (mechanical) part. The same remark applies for the fuel, lift and export gas streams.

\subsubsection{Exergy transformations}

The only chemical transformations (reactions) that take place on an oil and gas platform are the combustion reactions in the gas turbines, i.e. in the utility system. The outflows of the combustion chamber have a low heating value and a high temperature, in comparison to the inflows, illustrating that most chemical exergy is transformed into thermal exergy. In the processing plant, as no chemical reactions occur, the only changes in chemical exergy are associated with the mixing and separation operations.

The sum of the chemical exergy increases due to the separation effects amounts to about $560 \mathrm{~kW}$ for the start-life case, of which $50 \%, 42 \%, 6 \%$ and $2 \%$ take place in the gas treatment, separation, condensate stabilisation and recompression processes. The separation exergy increases to $620 \mathrm{~kW}$ in the peak case, with a share of $52 \%, 39 \%, 7 \%$ and $2 \%$, and decreases to $320 \mathrm{~kW}$ in the end-life case, with a distribution of $74 \%$, $12 \%, 14 \%$ and $2 \%$. This illustrates that the gas treatment process is of key importance for achieving the desired separation of the oil and gas phases. In all cases, the components in which most separation work is performed are the 2nd stage 2-phase separator in the separation train and the two scrubbers prior to the glycol dehydration.

\subsubsection{Exergy destruction and losses}

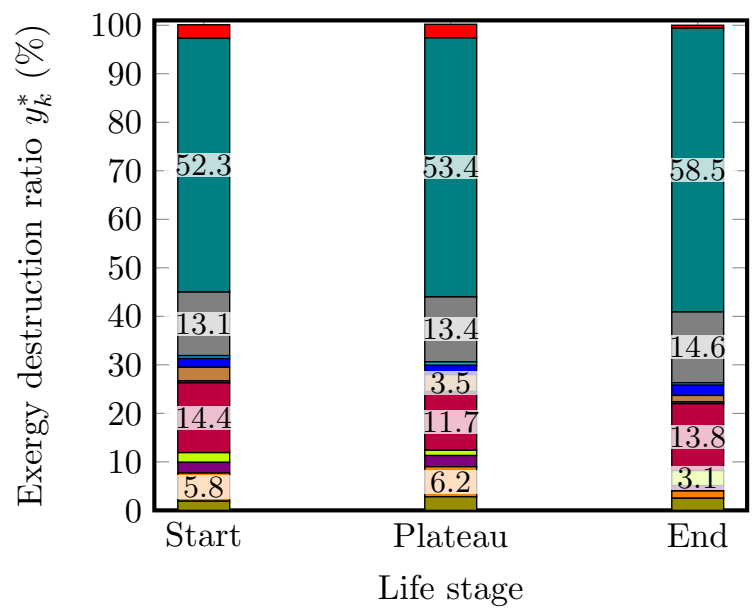

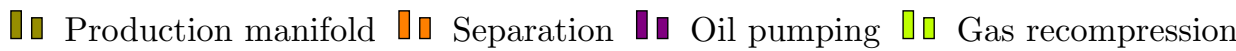

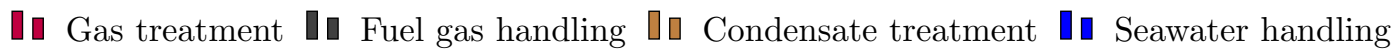

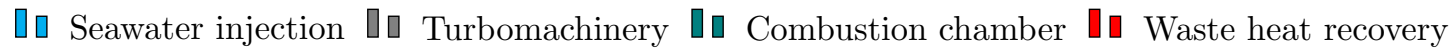

Figure 6: Distribution of the exergy destruction on an offshore platform at three life stages of the oil production.

The exergy destroyed on the platform amounts to 65,64 and $58 \mathrm{MW}$ in the start-life, plateau and endlife cases, while the exergy lost amounts to 28, 29 and $50 \mathrm{MW}$, respectively. The exergy destruction share between the processing and utility plants is nearly unchanged (65-70\% to 30-35\%) for the plateau, middecline and end-life cases (Figure 6). However, the distribution of the exergy destruction per sub-system changes significantly. The exergy destruction in the processing plant is highest in the plateau case and smallest in the end-life situation, ranging from 16 to $19 \mathrm{MW}$.

Most exergy destruction takes place in the production manifold and gas treatment at the beginning of the field exploitation, while it mainly occurs in the gas recompression as the field approaches its end-life. These findings suggest that the small decrease of the exergy destruction in the end-life case, compared to the two 


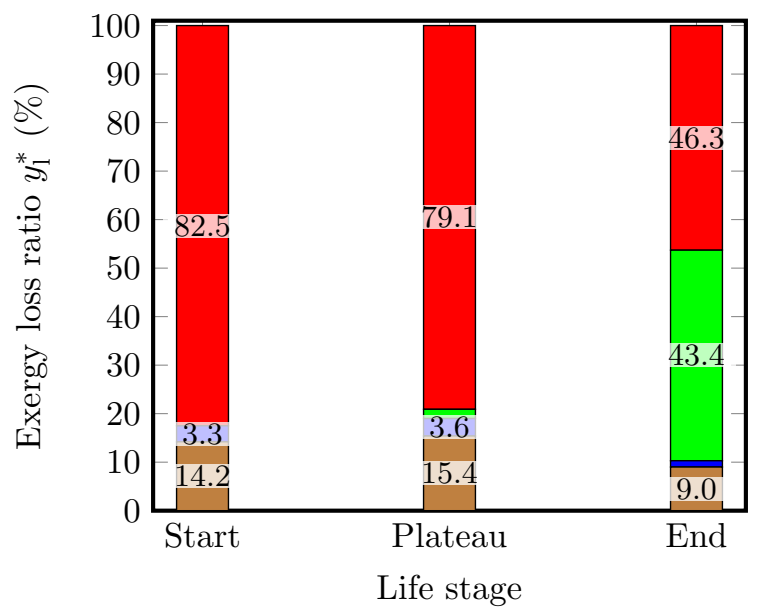

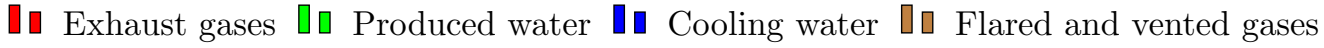

Figure 7: Distribution of the exergy losses on an offshore platform at three life stages of the oil production.

others, results from the smaller heating demand in the separation and condensate stabilisation processes, as the irreversibilities taking place in the heaters are reduced by more than $75 \%$.

On the contrary, the exergy losses of the overall platform rise with time (Figure 7), because of the greater flow of produced water. Smaller amounts of heat are required: the exhaust gases are therefore rejected with higher temperature and physical exergy.

The total exergy destruction and losses represent more than $150 \%$ of the total power consumption, and a further investigation illustrates in details their locations and causes (Figure 8):

- combustion chambers of the gas turbines (chemical reaction, mixing, friction and heat transfer);

- produced water rejection (only in end-life case, because of the large water production);

- exhaust gases exiting the waste heat recovery system (high temperature and physical exergy);

- coolers in the processing plant (large heat transfer across high temperature differences);

- compressors in the gas re-compression and treatment systems (low isentropic efficiency);

- anti-surge recycling (only in early-life and end-life conditions, because of a small gas production);

- valves in the production manifold (depressurisation of the reservoir fluids).

The specific exergy destruction per unit of produced gas and oil, on a standard volume basis, is about 70,50 and $210 \mathrm{kWh}$ per $\mathrm{Sm}^{3}$ of oil equivalent. It decreases as the hydrocarbon production rate rises, and increases sharply after the peak production is passed, because of the gas recirculation around each compressor and the smaller production rate. This performance indicator is more consistent than the absolute value of the exergy destruction rate, as it normalises the system inefficiencies to the useful output. It illustrates, as expected, that the offshore facility becomes less performant in the end-life phase of an oil field, as the plant handles oil and gas rates that are far smaller than the ones which the system was designed for.

Potential and kinetic exergies were not considered in this work: in practice, power is consumed to lift the water and reservoir fluids on-site, and the differences of height are considered in the calculations of the pressures and physical exergies. Kinetic exergy is destroyed in the wells and pipelines, as the velocity of the oil and gas streams should be reduced to ease the separation between the vapour and liquid phases. 

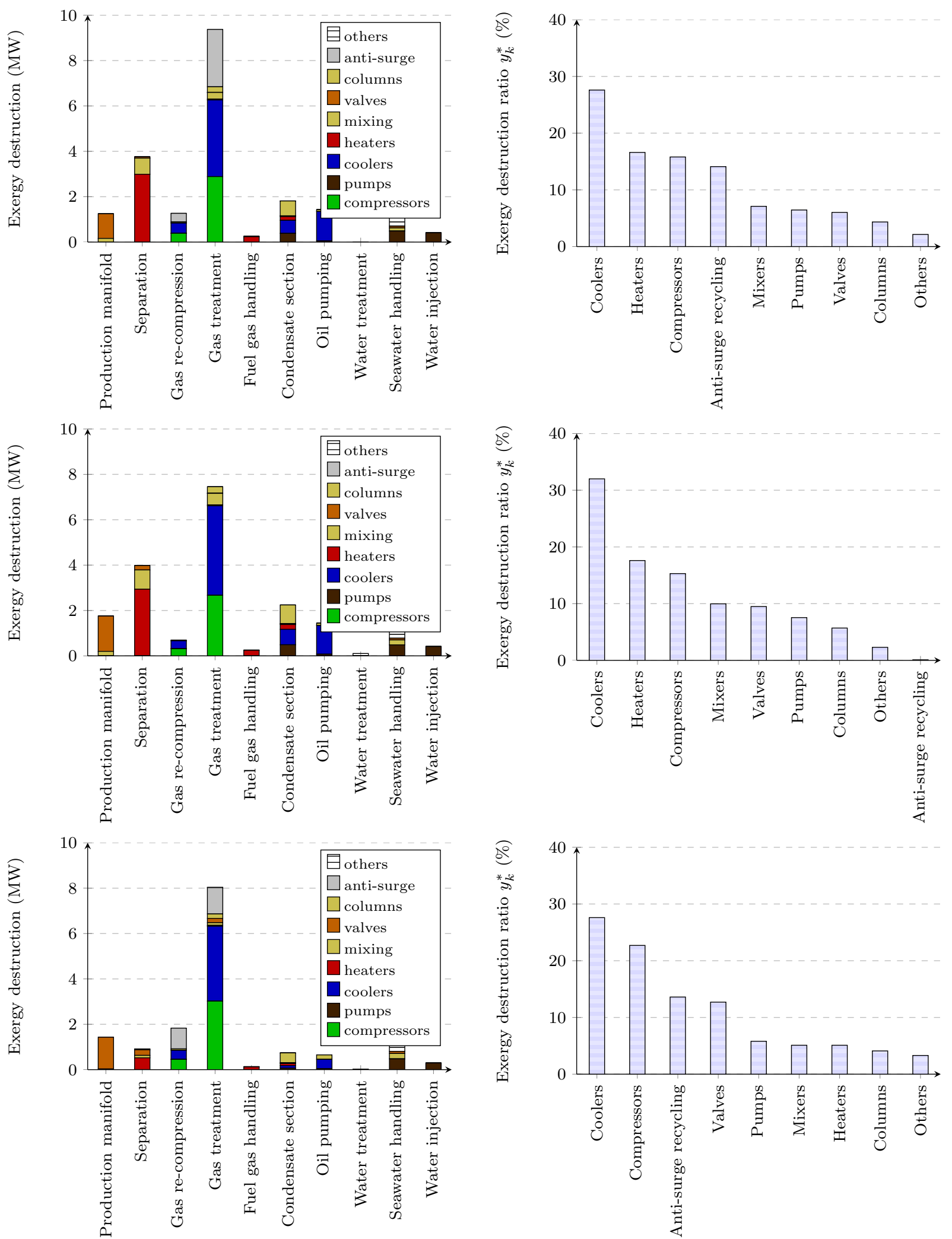

Figure 8: Exergy destruction share and ranking for the early-life, peak and end-life production, sorted by processes (left) and components (right), in the processing plant only. 


\subsubsection{Exergetic efficiencies}

The four gas compressors in the gas recompression and treatment sections display an exergetic efficiency of 70 to $80 \%$, which varies in a range of $\pm 5 \%$ over time. They have the highest performance in the peak production case, as they are designed for such operating conditions. The efficiencies for these turbomachinery components do not vary significantly over time, as the gas flow rates at their inlets are adjusted by gas recirculation, and regular service and maintenance activities are targeted to eliminate the negative effects of degradation and fouling.

The seawater coolers have an exergetic efficiency lower than $20 \%$, while the crude oil heater in the separation process has an efficiency of about $49 \%$ in peak conditions, and $37 \%$ in end-life ones. This sharp decrease results from the worse matching of the temperature profiles of the glycol loop and of the crude oil, illustrating the unbalanced behaviour of the heat exchanger. The gas turbines, which are run in part-load conditions, have an exergetic efficiency lower than $25 \%$.

\subsection{System improvements}

The combined findings of the total site and exergy analyses suggest that there are rooms for improving the performance of oil and gas platforms:

- the exergy destruction taking place in the combustion chambers $(\leq 40 \mathrm{MW})$ is mostly unavoidable, as it is caused by the chemical reactions, which are in essence irreversible processes. In theory, it could be reduced by adjusting the air-to-fuel ratio near the stoichiometric proportions or by allowing for higher reaction temperatures. However, a stoichiometric air-to-fuel ratio is generally not advisable, as a fraction of the hydrocarbons may be un-burnt, and an elevated temperature favours the formation of nitrous oxides following the Zeldovich mechanisms (thermal $\mathrm{NO}_{\mathrm{x}}$ ), while issues with the gas turbine materials may occur (sintering and melting). As argued in most exergy analysis works, these efforts would only result in minor improvements, and focus should then be kept on other components and losses. Newer gas turbines or gas engines, which are unfortunately heavy, may result in a higher efficiency;

- the exergy destruction occurring in the gas turbines $(\simeq 40-45 \mathrm{MW})$ can hardly be reduced, although the exergetic efficiency of this system is low compared to similar engines. The current power generation strategy of offshore platforms, i.e. the operation of multiple gas turbines at low load, lets little room for optimisation. Two possibilities are to reduce the power consumption of the oil and gas processing by improving this part of the system, which would in turn reduce the exergy destruction in the gas turbines, or to run most gas turbines at higher load and shutting down the remaining ones, if this is acceptable with regards to safety and operational considerations;

- the use of the exergy lost with the produced water is challenging. The chemical exergy of water $(\leq 16 \mathrm{MW})$ can hardly be used with the conventional technologies, and the high physical exergy $(\leq 7 \mathrm{MW})$ could only be used, through process integration, if there is a heating demand at temperatures lower than $50^{\circ} \mathrm{C}$. This may be interesting for platforms on which heavy oil is processed, as the heating demand is generally more significant on such facilities, but challenging, as the production of water is significant only in end-life cases;

- the gas recirculation to prevent surge is a significant cause for exergy destruction $(\simeq 5-10 \mathrm{MW})$ thorough the life cycle of an oil and gas platform, as it is practised in early- and end-life cases, because of insufficient flow rates of produced gas. Additional amounts of power are consumed, and the recycling of gas results in greater exergy destruction in the seawater coolers and compressors. The exergy destruction of the gas treatment process could be greatly reduced by using other control methods, downsizing the compressors or using parallel but smaller ones. The power consumption would decrease, leading to a higher export of gas and greater profits;

- the exergy destroyed in the production manifold $(\leq 3 \mathrm{MW})$, where all streams are mixed and depressurised to the operating pressure of the separation system, could, in theory, be recovered by 
integrating multiphase expanders. However, these technologies are not mature yet, and should be able to handle vapour-liquid-solid mixtures. The benefits may be limited in the end-life of an oil field, as the well pressures have decreased;

- finally, one of the main sources of inefficiencies is the rejection of exhaust gases at high temperature to the environment $(\leq 25 \mathrm{MW})$, combined to the heat transfer over large temperature gaps in the heat exchangers of the processing plant $(\leq 15 \mathrm{MW})$, using a glycol loop and cooling water. This results in significant exergy destruction in the beginning and peak production periods, and large exergy losses with the flue gases throughout the complete exploitation. The current utility system does not allow for recovering and using efficiently the large amounts of waste heat. An appropriate improvement would be to decrease the external heating requirements above the site pinch point and to target this energy demand more efficiently by matching the temperature levels of the heat source and receiver.

The rest of this study focuses on an improved use of the waste heat from the exhaust gases and hot gases, as these measures could reduce significantly the exergy destruction and losses of an offshore platform. The integration of heat pumping of the low-temperature heat below $130{ }^{\circ} \mathrm{C}$ to temperatures above $200{ }^{\circ} \mathrm{C}$ is not considered, because of the self-sufficient pocket between 60 and $100^{\circ} \mathrm{C}$ and since this would require a significant temperature lift.

\subsection{System integration alternatives}

The integration of SRC and ORC is investigated, optimising simultaneously the grass-root costs (minimisation), the power capacity (maximisation) and the local $\mathrm{CO}_{2}$-emissions (minimisation). The comparison of the optimal solutions is based on the peak and end-life production cases, as these two situations present the biggest differences with regards to the heating and cooling demands, and to the oil, gas and water production rates.

\subsubsection{Pareto-optimal solutions}

The optimal solutions obtained for the peak and end-life production cases can be compared based on performance indicators such as the net power capacity and the grass-root costs (Figure 9). The additional investment costs range between $\$ 9 \mathrm{M}$ and $\$ 11 \mathrm{M}$ if only a steam cycle is installed, assuming that the heat exchanger network is already on-site. The integration of a supplementary low-temperature cycle results in a sharp increase of supplementary $\$ 5 \mathrm{M}$ to $\$ 6 \mathrm{M}$, but allows for a greater power generation if needed. The greater costs are mainly caused by the additional equipment to be installed. The daily local $\mathrm{CO}_{2}$-emissions drop from about 430-450 to about 350-380 $\mathrm{t}_{\mathrm{CO}_{2}} / \mathrm{d}$, which corresponds to a net decrease of 12 to $18 \%$, if the total power output remains unchanged and the gas turbines operate at lower part-load. The export of natural gas increases in consequence, from 15 to $21 \%$, as less gas is consumed in the gas turbines. The $\mathrm{CO}_{2}$-avoidance cost varies between 27 and $33 \$ / \mathrm{t}_{\mathrm{CO}_{2}}$ when only a steam cycle is integrated, and between 30 and $36 \$ / t_{\mathrm{CO}_{2}}$ when a low-temperature power cycle is added.

\subsubsection{Steam network}

The most straightforward way to valorise the excess heat from the flue gases is to integrate a steam Rankine cycle. The process heat requirements can then be satisfied by (i) recovering heat from a fraction of the exhaust gases, rejected as a temperature as low as possible, or by (ii) processing all the exhaust gas flow through the heat recovery steam generator, and extracting steam at an intermediate pressure level.

However, the heating demand at a temperature of about $200^{\circ} \mathrm{C}$ would result in steam extraction at a pressure of at least 17 bar. This solution is sub-optimum, because the net power generation is maximised for a production level of 9 to 12 bar. Two configurations are preferred (Figure 10): the first one consists of implementing the steam network after the waste heat recovery loop, while the second one relies on a splitting of the exhaust gas flow, a fraction being routed to the heat recovery steam generator, the remaining one being used for process heating. The first configuration may be preferable in practice because the mass flow of the exhaust gases would be completely utilised by the steam cycle. The second one was only introduced 

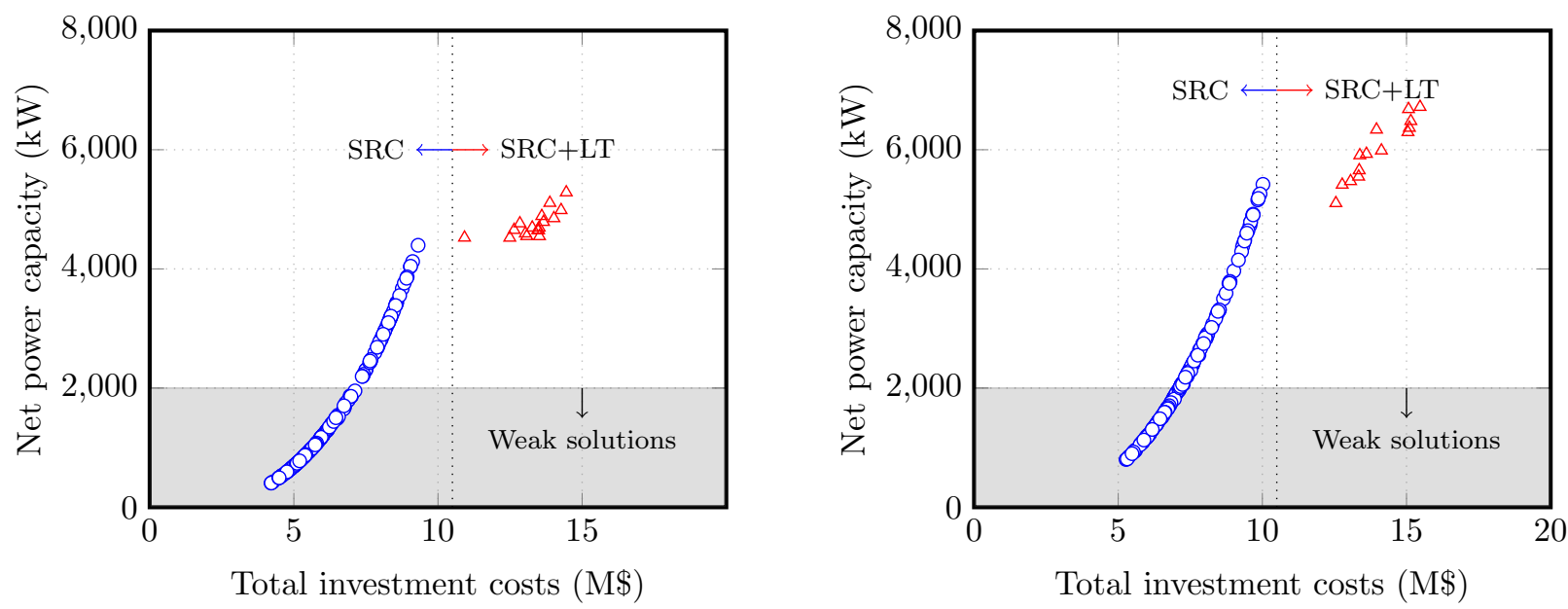

Figure 9: Pareto-optimal solutions for the integration of steam Rankine cycles and low-temperature power cycles, for the peak (left) and the end-life (right) situations. SRC denotes Steam Rankine Cycle and LT Low-Temperature power cycle.

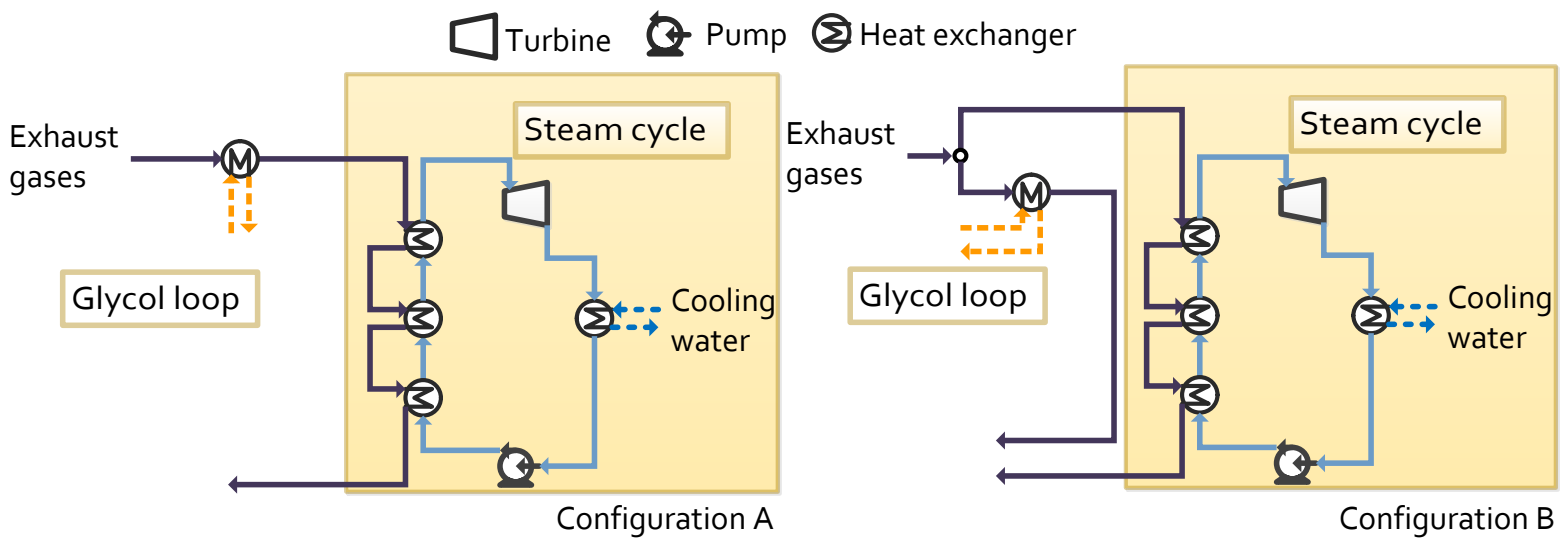

Figure 10: Optimal configurations of the steam Rankine cycle in the oil and gas facility. 
to discuss the flexibility of the power and heat cogeneration system, for different life cycle stages of the platform.

The advantage of integrating a steam network can be demonstrated with the Integrated Composite Curves [44,66], which illustrate how well the steam Rankine cycle is integrated within the remaining processes of the oil and gas system (Figure 11). The area between the steam network and the other process stream curves corresponds to the exergy that cannot be further recovered in the heat exchanger network. The two cases that are shown correspond to two steam network configurations present on the Pareto frontier, for which the net power capacity ranges in the top $5 \%$ of all the displayed solutions. The comparison of the peak and end-life cases shows that solutions that may be optimum for the peak case may not be optimum for the end-life case, and vice-versa.

In the 1st case, the steam production (evaporation) takes place below the temperature of the condensate reboiling process $\left(\simeq 200^{\circ} \mathrm{C}\right)$. The steam generation, and therefore, the power production, are limited by the heating demands of the condensate reboiling and oil heating demands, as illustrated with the two utility pinches located at about $55^{\circ} \mathrm{C}$ and $190^{\circ} \mathrm{C}$. In the 2 nd case, the steam production takes place above the condensate reboiling temperature, and the power production is limited by the low temperature of the flue gases. These differences illustrate the impact of large heating demands on the optimal operating conditions of the SRC, and suggest that caution should be exercised when choosing the conditions at which the SRC should be designed.
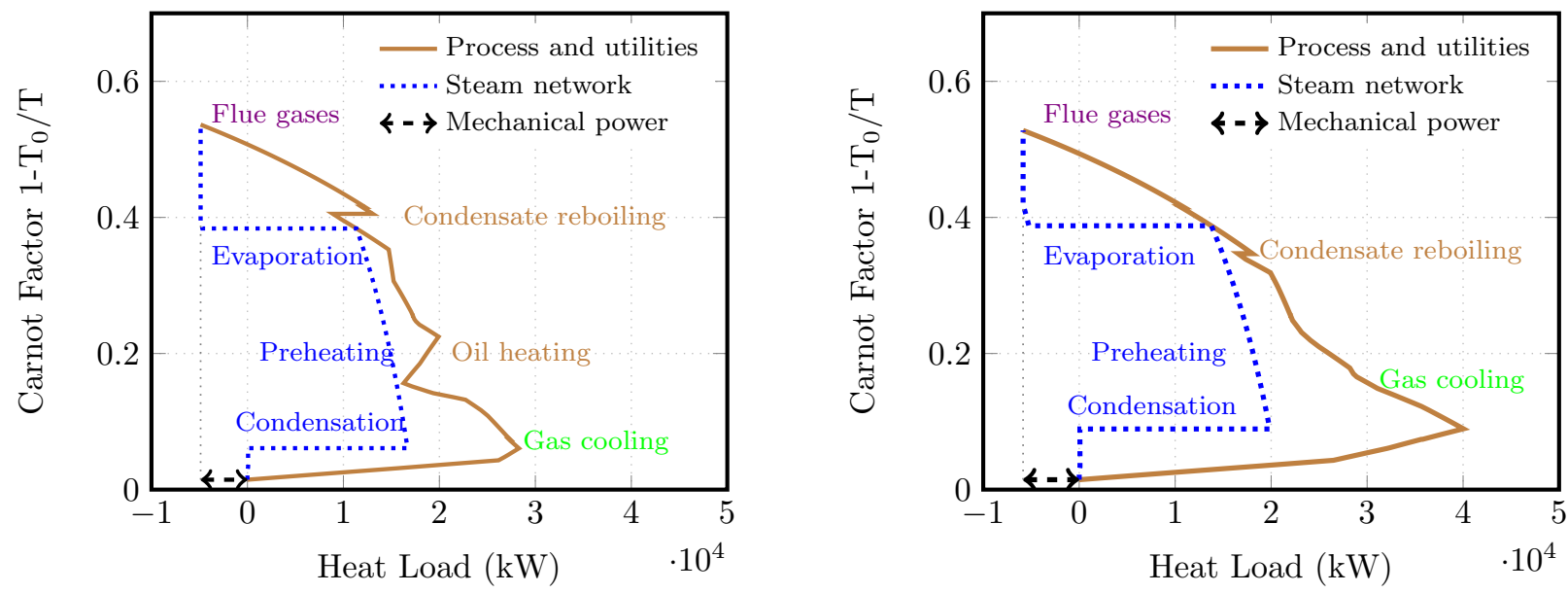

Figure 11: Integrated Composite Curves, on an exergy basis, of the steam Rankine cycle within the oil and gas platform, for the peak (left) and end-life (right) productions, without heat exchange restrictions.

The net power capacity of the steam Rankine cycle is particularly sensitive to design parameters such as the evaporation and condensation pressures, as well as the allowable vapour fraction at the outlet of the steam turbine (Table 3). The standard deviations for decision variables such as the superheating approach are higher than for other parameters: this suggests that the maximum power capacity of the steam network and the superheating temperature are not directly correlated. For all life stages, the steam production level varies in the range 9-12 bar, while the condensation level varies between 0.05 and 0.10 bar. The steam is condensed using cooling water from the processing plant, rather than using additional seawater, which has a lower temperature but should be lifted on-site. The maximum power capacity of the steam network ranges between 4800 and $5800 \mathrm{~kW}$, and the smallest maximum corresponds to the peak case, as there is a greater heating demand, and thus a smaller quantity of waste heat in the exhaust gases.

In the case that direct heat recovery between process streams is not feasible, the integration of the steam Rankine cycle is more challenging in plateau production cases. The external heating demand is higher, resulting in a temperature drop at the outlet of the waste heat recovery system with the heating medium.

The integration in end-life cases is generally less challenging, as the heating demand has decreased with the oil production. In this situation, the temperature at the inlet of the steam boiler was about 25 to $30{ }^{\circ} \mathrm{C}$ 
Table 3: Optimal design parameters for the steam Rankine cycle, for each production period. These numbers are the average means of the decision variable values for the configurations yielding the greatest power generation. The numbers in parentheses correspond to the standard deviations.

\begin{tabular}{lrrrr}
\hline & Production level (bar) & Superheating $(\Delta \mathrm{K})$ & Condensation level (bar) & Vapour fraction $(-)$ \\
\hline Begin & $10.6(14 \%)$ & $24.0(18 \%)$ & $0.07(43 \%)$ & $0.86(1 \%)$ \\
Peak & $9.8(13 \%)$ & $12.9(71 \%)$ & $0.05(30 \%)$ & $0.86(1 \%)$ \\
End & $11.8(12 \%)$ & $20.6(30 \%)$ & $0.11(35 \%)$ & $0.87(1 \%)$ \\
\hline
\end{tabular}

lower, resulting in a subsequent drop of the stack temperature for maintaining the same power production.

In general, the integration of the steam Rankine cycle results in a drop of the exergy lost with the exhaust gases of about $10 \pm 1.5 \mathrm{MW}$, while the exergy lost with cooling water increases by $1.2 \pm 0.2 \mathrm{MW}$. Exergy is destroyed in the cycle at rates of about $1.5 \pm 0.3 \mathrm{MW}, 1.2 \pm 0.2 \mathrm{MW}$ and $0.7 \pm 0.1 \mathrm{MW}$ in the steam boiler, turbine and condenser.

\subsubsection{Low-temperature power cycle}

A second possibility for improving the thermodynamic performance of this system is to valorise the heat and exergy available at moderate temperatures from the produced gas $\left(\leq 150^{\circ} \mathrm{C}\right)$, using a low-temperature power cycle using carbon dioxide, propane, or a mixture of hydrocarbons (Figure 12).

The cycles can operate either on sub-critical or transcritical cycles: the optimisation results suggest that the most efficient cycle would be a transcritical cycle using a mixture of ethane and propane, in proportions, on a mass basis, varying between $50 \%-50 \%$ to $70 \%-30 \%$. Although these cycles display a thermal efficiency as low as $10 \%$, their integration can result in an additional net power generation of 1.5 to $2.5 \mathrm{MW}$, depending on the life production stage and on the rate of the produced gas (Figure 13).
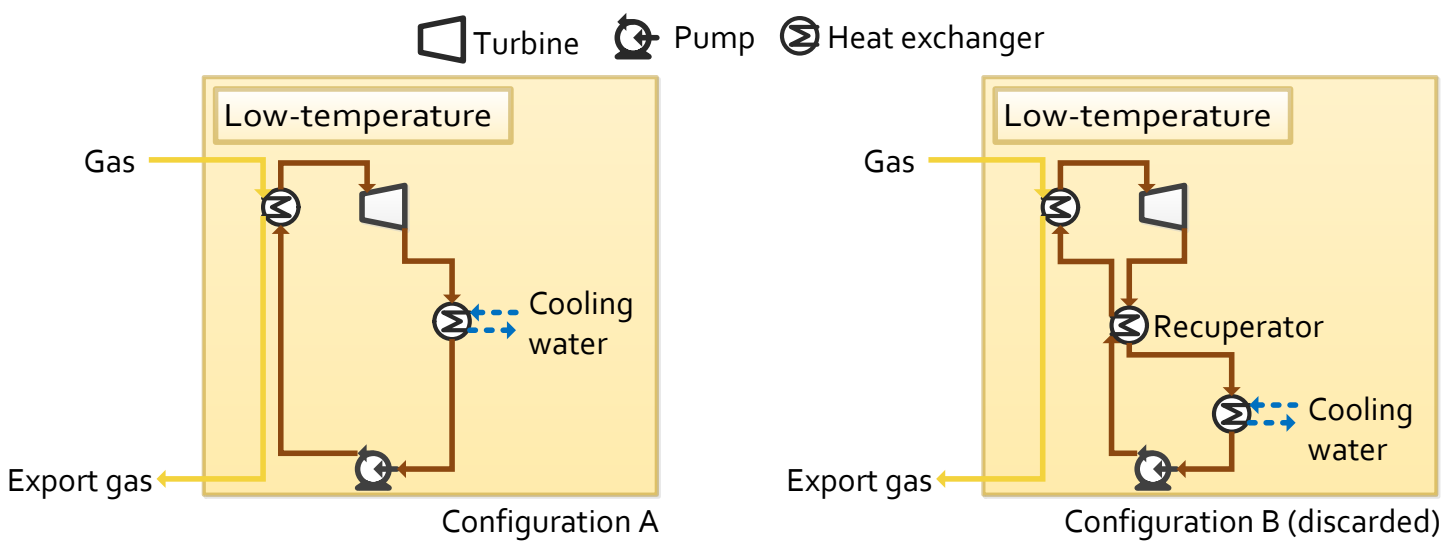

Figure 12: Optimal configuration of the low-temperature power cycle in the oil and gas facility.

In an ideal situation, where there are no heat exchange restrictions, the implementation of such a cycle seems more promising in an end-life situation, since the heat from the produced gas cannot be utilised. In a peak production case, the waste heat from the gas streams could be partly recovered for satisfying the heating demand of the oil, and little waste heat could be utilised further.

As for the steam Rankine cycle, the performance of the low-temperature power cycle is directly correlated to a few design parameters, such as the condensation and production levels, the temperature after superheating and the ethane fraction (Table 4). The optimal low-temperature power cycles, i.e. the ones with the greatest power generation, operate between $20^{\circ} \mathrm{C}$ and $170^{\circ} \mathrm{C}$, and recover heat from the gas streams in the treatment process and from the condensate exiting the stabilisation column. In practice, the design of 

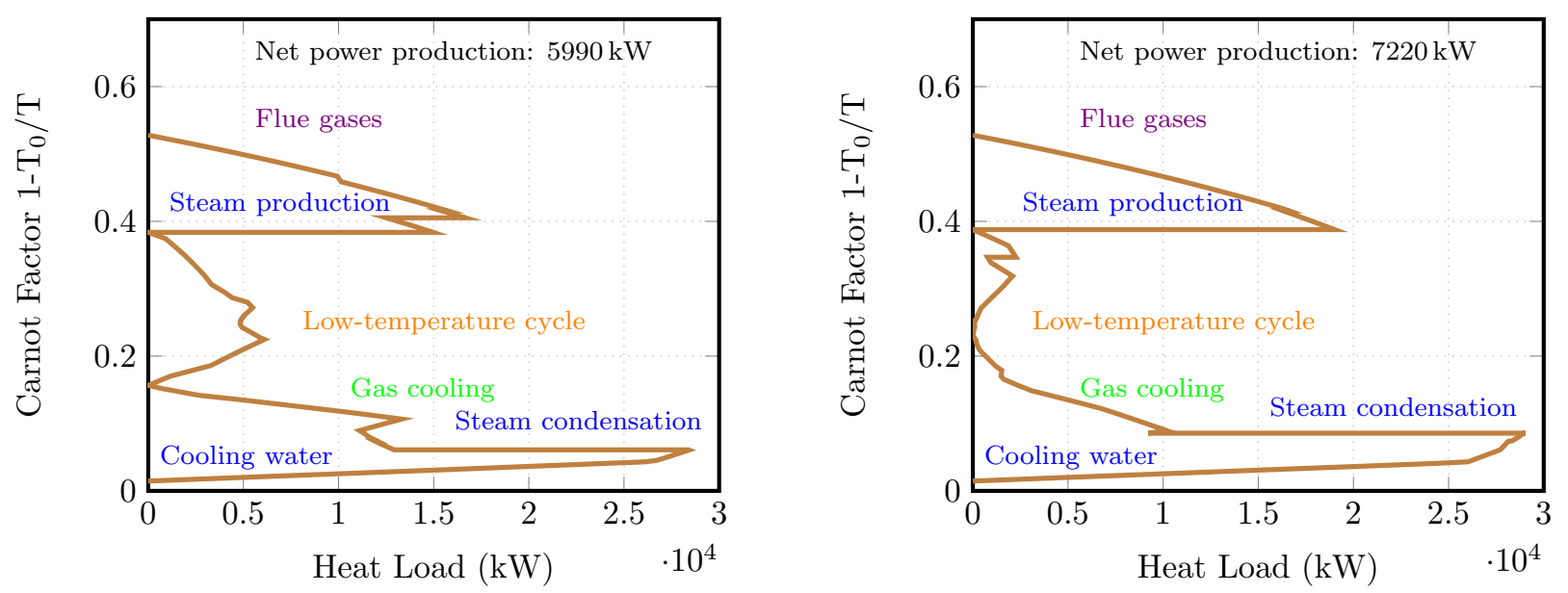

Figure 13: Balanced Grand Composite Curves, on an exergy basis, of the oil and gas platform system, including a steam Rankine and a low-temperature power cycles.

such a cycle would be challenging and costly, as the working fluid should be evaporated and superheated in several heat exchangers.

Table 4: Optimal design parameters for the low-temperature power cycle, for each production period. These numbers are the average means of the decision variable values for the configurations yielding the greatest power generation. The numbers in parentheses correspond to the standard deviations. The term condensation level refers to the temperature at the outlet of the condenser, i.e. when the working fluid is in a saturated liquid state.

\begin{tabular}{lrrrr}
\hline & Condensation level $\left({ }^{\circ} \mathrm{C}\right)$ & Production level (bar) & Superheating $\left({ }^{\circ} \mathrm{C}\right)$ & $\mathrm{C}_{2} \mathrm{H}_{6}(\%$ molar $)$ \\
\hline Begin & $19.2(2.8)$ & $77.5(4.0 \%)$ & $174(6.1)$ & $0.80(21 \%)$ \\
Peak & $23.1(2.6)$ & $77.2(3.6 \%)$ & $177(14)$ & $0.73(21 \%)$ \\
End & $20.4(4.1)$ & $69.9(11 \%)$ & $162(9.2)$ & $0.51(6 \%)$ \\
\hline
\end{tabular}

In the case that no heat recovery is feasible between the oil and gas streams, a cost-efficient alternative is to utilise the waste heat from one single hot stream, using the heat from the gas to be exported in the final heat exchanger. Additional power can be generated, while having a relatively compact and light system including only four components. In this situation, and considering the end-life conditions, the working fluid, with a composition of $40 \%$ ethane and $60 \%$ propane, operates between $23^{\circ} \mathrm{C}(19.5$ bar $)$ and $144{ }^{\circ} \mathrm{C}(56$ bar $)$. The cycle can provide a net supplement of power of $590 \mathrm{~kW}$, which corresponds to a thermal efficiency of $8.3 \%$. For the latter case, exergy is destroyed at rate of about 250,210 and $200 \mathrm{~kW}$ in the boiler, turbine and condenser, while the exergy lost with the additional cooling water amounts to nearly $120 \mathrm{~kW}$.

\subsubsection{Double glycol recovery loop}

A third possibility for enhancing the system performance is to recover the heat from the exhaust gases in three steps: (i) in a first glycol loop, to provide heating at high temperatures $\left(\simeq 200^{\circ} \mathrm{C}\right)$ in the condensate stabilisation column, (ii) in a steam network, to produce additional electricity, and (iii) in a second glycol loop, to provide heating at low temperatures $\left(\simeq 85^{\circ} \mathrm{C}\right)$ in the crude oil heater (Figure 14). This configuration allows for a better match of the temperature profiles between the exhaust gases and the several heating demands, as the oil heating and condensate reboiling take place at dissimilar temperatures. The exhaust temperature at the inlet of the heat recovery steam generator is about 10 to $15^{\circ} \mathrm{C}$ higher, and this results in a better efficiency of the steam cycle and a greater power generation. The increase of the net power capacity is estimated to be about $8 \%$, for the same temperature approach and pressure level (Figure 15) in the HRSG (Heat Recovery Steam Generator). The integration of such a configuration appears promising, especially in cases where the heating demands of the oil and gas processing plant are minor, or take place 
at very dissimilar temperature levels. This solution is also interesting from an operational point of view, since the two glycol loops can be run and controlled independently. The total flow of glycol in the waste heat recovery loops is smaller than in the baseline case, meaning that the pumping work is also reduced.

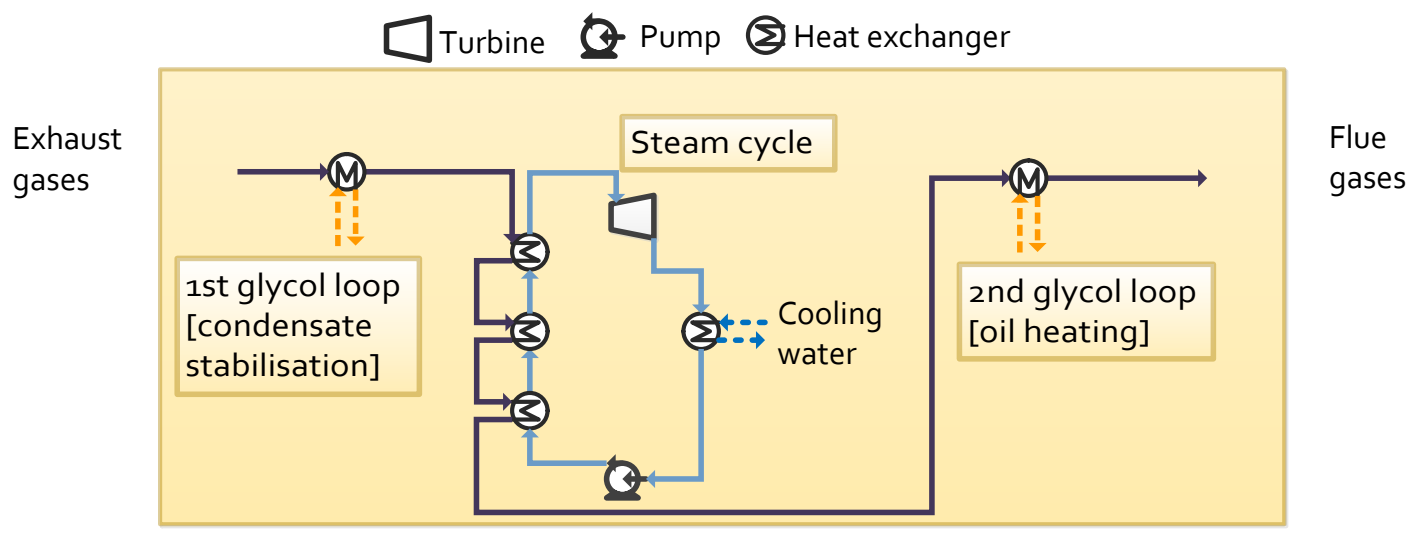

Figure 14: Integration of a double glycol loop cycle.

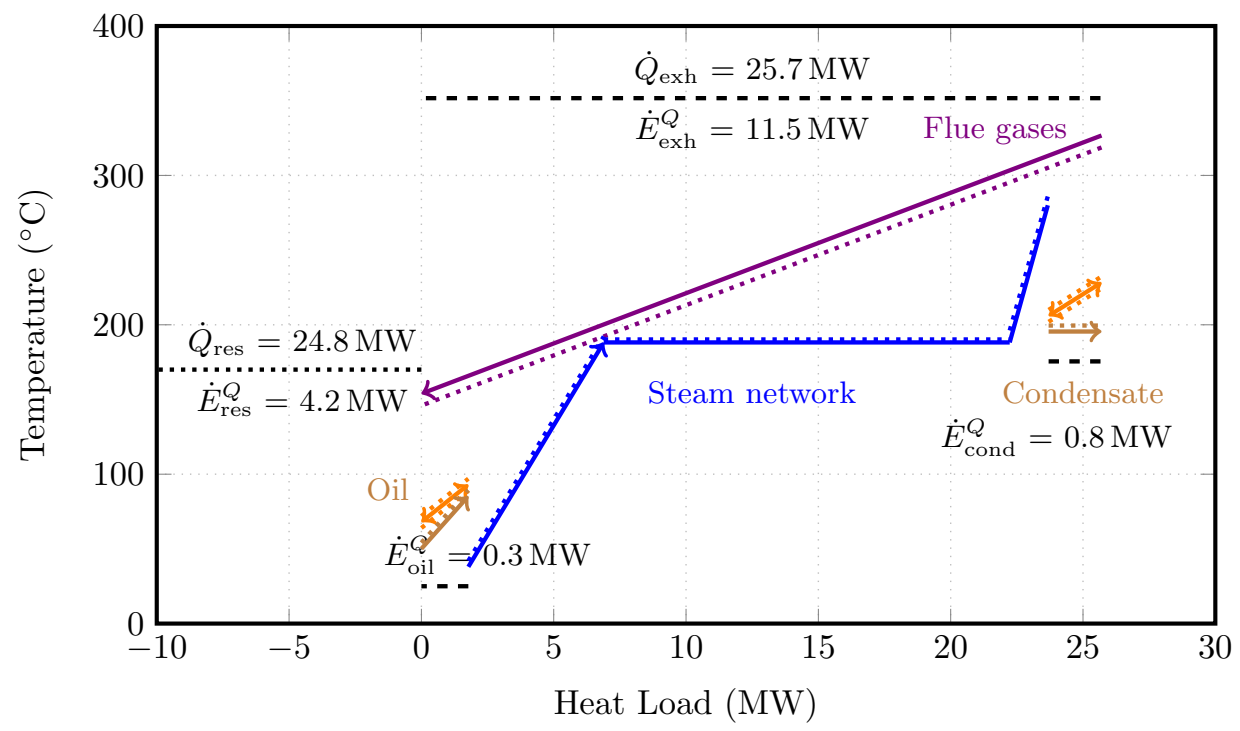

Figure 15: Temperature-enthalpy diagram of the site heating demand for the end-life production case, with integration of a steam network and a double circuit glycol loop. They are illustrated with the thermodynamic (process), technology (glycol loop) and utility (exhaust gases) requirements. The full lines correspond to the real temperatures, the dotted lines to the corrected ones (i.e. adjusted with the individual temperature differences $\frac{\Delta T}{2}$ ), and the dashed ones to the energy demands. For more readability, all the residual heat is not shown in the figure.

\section{Discussion}

\subsection{Performance of oil and gas platforms}

\subsubsection{Comparison of different offshore facilities}

There a few assessments of the performance of real-case offshore platforms in the scientific literature, which are, namely, the works of Voldsund et al. [25,67], Nguyen et al. [26] and Oliveira and Van 
Hombeeck [24]. However, these studies focus on the oil and gas processing plant solely, without considering the utility plant, and the effects of the variations of the petroleum production are not investigated.

The first platform investigated by Voldsund et al. [25,68,69], and called Platform A in a further work [67], has been in operation for about 20 years. The Voldsund's facility processes a reservoir fluid with a high methane content, which results in a gas-to-oil ratio of about $2800 \mathrm{Sm}^{3} / \mathrm{Sm}^{3}$, against $55 \mathrm{Sm}^{3} / \mathrm{Sm}^{3}$ for the facility presented in this study, in peak conditions. The GOR and WOR currently increase, while the oil production has exceeded its peak, and the gas compressors of the gas treatment section run at full capacity. The situation at this field is therefore similar to the simulated peak production case in the present work.

The second platform that was studied (Platform B), has been in operation for about 10 years. However, it processes mostly gas and the export pressure is lower (118 bar) than the inlet one (123-155 bar), making the comparison with the present cases more difficult. The heating demands for Platforms A and B are minor, amounting to a few hundred $\mathrm{kW}$ for preheating the fuel gas entering the power generation sub-system. The third platform (Platform C) processes heavy oil, and the gas-to-oil ratio was initially small: the produced gas is injected along with imported gas into the reservoir for lift and enhanced oil recovery purposes. Heating is required on that platform to ease separation between the oil and gas phases, and the demand exceeds $7 \mathrm{MW}$ on an exergy basis. The cooling demands for these platforms range in the same order of magnitude as the one presented in this study.

Oliveira and Van Hombeeck [24] studied a real-case oil platform located in another oil producing region, which is the Brazilian Basin. The water cut ( $~ 79 \%$ on a molar basis) and the total oil production $(285 \mathrm{t} / \mathrm{h})$ are in the same order of magnitude than for the present platform, in end-life situations. The main difference lies in the heating demand, which is about $28 \mathrm{MW}$ : at the difference of the Norwegian platforms, the fuel gas consumption is driven by the heating requirements, and not by the electricity ones. Large quantities of exergy are as well consumed and destroyed in the crude oil heater, and ways to improve the heat exchanges taking place on the platform are discussed.

These five platforms (i) operate under various natural (e.g. GOR and WOR) and boundary (e.g. export pressure) conditions, (ii) follow different operating strategies (e.g. gas import, lift, export and seawater injection), and (iii) exploit a field at a different life stage (e.g. start-life, plateau and end-life). The same trends were observed for the start-up, peak and end-life phase of the field production.

\subsubsection{Efficiency trends of oil and gas processing}

The most common field events that have an impact on the efficiency of oil and gas processing are listed as follows, based on the observations of the platform of study. Their consequences are expressed in energy and exergy terms, and possible energy efficiency measures, which shine from the previous comparisons, are proposed.

\section{Boundary conditions.}

- Reservoir and export pressures: a large differential between the reservoir and separation pressures results in (i) high power consumption in the gas treatment process to satisfy the gas export or injection requirements, and in (ii) large exergy destruction in the production manifolds (2-10 MW). Two possibilities are (i) to operate the production manifolds at multiple pressure levels, to reduce the compression demand, and (ii) to install multiphase expanders, to produce power from the pressure reduction process. However, the reservoir pressure decreases over time, implying that more energy is required to lift the reservoir fluid on-site, and that less exergy could be recovered. The well-fluids could possibly be re-routed from high-pressure manifolds to medium-pressure ones in such cases;

- Reservoir temperature: the heating and exergy demands of an offshore platform are directly correlated to the reservoir temperature, as the separation between the oil, gas and water phases generally takes place at temperatures between 50 and $100^{\circ} \mathrm{C}$. There may be either gas or produced water streams available in these ranges of temperature, and this suggests that process integration efforts should be regarded carefully from the beginning of the exploitation. Reliability aspects should be considered, to ensure a secure oil production; 
- Reservoir fluid composition: the content of medium- and heavy-weight hydrocarbons has a direct impact on the process design, as significant heating and the implementation of distillation columns may be required to achieve the desired separation between the oil and gas phases. This heating demand may be significant and decreases with the oil production. This indicates that the utility plant should be flexible enough to satisfy both the heating and power requirements, and that the implementation of a steam Rankine cycle can be interesting;

- Gas production: the gas-to-oil ratio generally increases over the field life, but the absolute gas production decreases after reaching a production peak. High gas production leads to high power consumption in the gas re-compression and compression sections because of the large flows to handle. Low gas production, in start- and end-life situations, results in gas recycling around the compressors for operating and safety issues, which contributes to high exergy destruction in the recirculation loops (valves and coolers) as well as in the compressors. The downsizing of the compressors and the operation of parallel compression trains seem to be two interesting alternatives. The gas flows entering each compressor can be adjusted to ensure that the compression trains are run at full-load, switching on or off a compression train depending on the total gas flow;

- Water production: the water-to-oil ratio continually increases with time, as well as the absolute water production. The exergy destruction in the produced water system is neglectable (under a few hundreds $\mathrm{kW}$ ) at the level of the processing plant, but more separation work should be performed to separate the oil, gas and water phases.

Operating strategies.

- Gas lift and injection: gas lift and injection are energy-intensive techniques practised to maximise the liquid throughput. Gas should be compressed to a pressure greater than the hydrostatic pressure of the reservoir fluid, and this impacts both the power (compressors) and the cooling demands (seawater);

- Water injection: as for gas lift, water injection is an energy-intensive process, as large quantities of power are consumed in the pumping operations. Seawater has been used to support the reservoir pressure and enhance the oil displacement. The use of produced water is challenging: solid sulphates (e.g. $\mathrm{BaSO}_{4}$ ) may precipitate, and seawater should be added to avoid reservoir deterioration. The use of cooling water is, on the other hand, already practised on several platforms such as Ekofisk [4] and allows for smaller power consumption and moderate exergy losses;

- Gas import: a low gas production may result in gas import from another field, either for gas lift and injection or for power generation purposes. Depending on the import pressure, further compression and cooling may be required;

- Equipment redundancy: the use of redundant components in parallel, such as gas turbines, leads to lower efficiencies of these components, and additional power consumption. A different design may be preferable, by using 3 gas turbines instead of 2, which would operate at a better load point and with a higher efficiency. The integration of bottoming cycles to gas turbines may be considered, as it adds more flexibility and stability to the power generation plant.

These trends and variations suggest that a high efficiency over the whole operating range is of interest, rather than a very high efficiency at peak conditions, and a significantly lower one in part-load, during the other production phases.

\subsection{Performance improvements}

\subsubsection{Steam and organic Rankine cycles}

Integrating a waste heat recovery cycle after the gas turbines allows for a greater power capacity, if required, or for a lower fuel gas consumption and smaller $\mathrm{CO}_{2}$-emissions and taxes. It is generally easier in end-life conditions, as the heating demand is negligible. For platforms that process, for instance, hightemperature volatile oils, the heating requirements are generally minor during the complete exploitation, and this eases the integration of the waste heat recovery plant. 
Steam Rankine Cycles. The implementation of steam Rankine cycles on oil and gas platforms is discussed in the works of Kloster et al. [4,5], in the case of the North Sea region. The engineering challenges are also emphasised in Nord and Bolland [70,71], but this technology is considered as mature enough to be integrated offshore. The installation of organic Rankine cycles on offshore facilities has never been performed. The high compactness and low weight compared to a conventional steam Rankine cycle may favour the implementation of such cycles on oil and gas platforms, because of the stringent space and weight constraints, at the expense of additional chemicals on-site.

The heating demand is, at present, satisfied on most offshore platforms by recovering the waste heat from the exhaust gases, and by adjusting the temperatures of an intermediate heat transfer loop (e.g. glycol or pressurised water). On platforms on which the heating demand is significant, the integration of a steam Rankine cycle is of particular interest, as the heating supply from the waste heat recovery plant can be controlled by adjusting the steam extraction $[4,5]$. The extracted steam may either be used directly or indirectly in the processing plant. As the heating demand over the field life decreases, the amount of extracted steam can be reduced, and the steam cycle operates then as a slave of the gas turbine. The disadvantage of such a solution is its consequent weight [70,71]. This solution is viable only if the turbine exhaust gases have a temperature high enough to allow for steam production at pressures above 15 bar.

There are two other possibilities, which are adapted to the case of gas turbines with moderate exhaust temperature $\left(\leq 400^{\circ} \mathrm{C}\right)$. The steam cycle can be integrated after a first waste heat recovery system (Configuration A), or the exhaust gases at the outlet of turbine can be split (Configuration B), and only a fraction of the exhaust gases flow into the waste heat recovery system to heat up the glycol medium. In some cases, depending on the temperature levels at which the heating demands take place, the integration of two waste heat recovery loops instead of a single one may be beneficial, as it would result in a higher exhaust temperature at the inlet of the steam network, and thus in a greater power generation.

The main drawback of Configuration $\mathrm{A}$ is that the bottoming cycle should then be designed either for low flow rates of exhaust gases, which would result in a small power capacity, or for high flow rates, and the cycle would then operate in severe off-design behaviour during the start- and peak-production periods.

Organic Rankine Cycles. The integration of organic Rankine cycles is more challenging, as these cycles cannot be used to supply the heating demand, as a steam cycle with steam extraction could do. The ORC should be implemented after the waste heat recovery module, as in Configuration A, or a large fraction of the flue gases should be processed separately, as in Configuration B. The implementation of these cycles is interesting only under these conditions:

- the heating demand is minor during the entire field life, which is the case if the well-streams have a high temperature at the inlet of the separation process $\left(\geq 50-60^{\circ} \mathrm{C}\right)$, and if the reservoir fluid contains only small quantities of medium- and heavy-hydrocarbons;

- the heating demand was significant in the beginning of the field exploitation, but the ORC is integrated as a retrofit solution when the production runs towards its end-life, i.e. the current heating demand is not significant;

- the cycle is installed as a complement to another waste heat recovery system: the ORC is implemented on the exhaust gases of one or two gas turbines, and a heat transfer loop recovers the waste heat from other gas turbines on-site;

- the flue gases at the outlet of the gas turbines have a moderately high temperature, and the ORC is, in these conditions, more efficient than a conventional SRC;

- space and weight are particularly limited, and the ORC is then more suitable than a SRC, as its components are smaller. 


\subsubsection{Low-temperature power cycles}

Integrating a low-temperature power cycle for recovering heat from the export gas compression seems promising, as large quantities of heat are dumped into the sea during the field exploitation. The exergetic efficiency of the gas coolers is typically small $(\leq 15-20 \%)$ and these components are responsible for a high dumping of heat into the sea and large exergy destruction. As emphasised by Rohde et al. [61], using the aftercooling waste heat, i.e. the heat released by the exported gas after the final compression stage, is challenging because of the low temperature of the heat source $\left(\leq 150^{\circ} \mathrm{C}\right)$ and the variations of the gas flow rate and properties over time.

Their work and the present study support the interest of integrating such a cycle on offshore facilities if the gas production rates are large (high GOR of the petroleum field). The possibility of using the waste heat in a combined system, i.e. if heat is recovered from two or more gas coolers, should be considered. It may result in operational challenges, as the working fluid should be able to cool all gas streams to the required temperatures, which are in the range of 20 to $30^{\circ} \mathrm{C}$.

No general rules can be directly derived for the integration of such processes, except that such cycles should rather be implemented on platforms processing large gas flows, and preferably before the gas peak production. Thorough techno-economic assessments should be conducted to analyse the compactness and economic viability of these installations, with regards to the specific features of each facility.

\subsection{Significance and limitations}

\subsubsection{Errors and uncertainties}

The total site and exergy analyses were based on (i) values received from the system database, given on a hourly to daily basis, (ii) fiscal declarations to the Norwegian Petroleum Directorate, given on a monthly to yearly basis, (iii) assumptions and hypotheses discussed with the operators and experts in this field, (iv) process flow diagrams and identifiers, and (v) reference books and literature. The data used for the model calibration builds therefore on steady-state and post-processed data, which were, in some cases, averaged or kept constant inside the database. Instantaneous changes in temperatures, power and heating loads were not considered.

The measurement uncertainties, combined to the uncertainties from the thermodynamic modelling, have been assessed for one North Sea oil and gas platform [67]. The highest uncertainty is found in the prediction of the power consumption and exergy destruction in the oil export section, which can reach up to $40 \%$. On the contrary, uncertainties related to the gas processing are small, and do not exceed $1 \%$ for the power consumption, and $5 \%$ for the exergy destruction. The uncertainties of the heating and cooling demands have not been assessed, but it is expected that they are in the same order of magnitude. These issues should be considered when integrating possible improvements to the current system, to ensure a safety margin. The collection of more accurate data on the plant status could help in improving similar works.

\subsubsection{Thermodynamic analysis methods}

The present work supports the attractiveness of energy- and exergy-based assessments for pinpointing and quantifying the system inefficiencies, as discussed in Rivero [65]. The two methods used in this research (i.e. total site analysis and exergetic accounting) complement effectively each other, as they describe and address different aspects (energy requirements and entropy generation) of the performance of an oil and gas platform. The combinations of the findings presented in this work and in the scientific literature $[23,25,26,67]$ may be used for a preliminary analysis of the performance of oil and gas platforms, and for establishing guidelines towards designing new ones.

Caution should be exercised when extending the present conclusions, as different offshore facilities present different field properties and operational challenges. For instance, the variation of the heating demand strongly depends on the oil properties (composition and temperature): the implementation of a waste heat recovery cycle such as SRC or ORC should be considered carefully, regarding all the possible interactions between the power generation and the oil and gas processing plants, and considering site-scale integration aspects. 


\subsubsection{Performance monitoring}

The use of pinch- and exergy-based tools can be considered promising for:

- setting and comparing performance benchmarks [25], which would complete indicators such as the specific power consumption and energy intensity, already in use in the industry [6]. The implementation of these indicators with real-time data could allow for a greater optimisation of the system, a reduction of the energy use, and an increase of the economic profits;

- evaluating the potential for improving the facility, by comparing the minimum energy requirements to the actual ones (total site analysis) and by assessing the efficiency of each important component (exergetic accounting);

- analysing the life performance of the facility, and such efforts could help in drawing guidelines for improving current and future platforms, and enhance the general knowledge on the impacts of different field events.

\section{Conclusion}

The life performance of an oil and platform was assessed by modelling the facility in three exploitation periods, and by conducting a total site and an exergy analysis. The total site analysis highlighted the difficulties for recovering the system heat because of the temperature and enthalpy mismatches between process streams, and the inadequate temperature levels of the utilities. The exergy analysis showed that most exergy destruction was taking place in the gas turbines, which is mostly unavoidable, and that most other inefficiencies were related to the heat exchanges, compression and anti-surge recycling operations. The irreversibilities in the heat exchangers were significant during the whole exploitation period, while the ones caused by gas recirculation were remarkable only in the start- and end-life production periods. The major exergy losses were associated with the rejection of high-temperature exhaust gases, since only a minor fraction of this waste heat was recovered. The energy demands, exergy destruction and losses change significantly with time, with an absolute variation of about 15, 7 and $22 \mathrm{MW}$, respectively, because of the smaller oil production and the increasing water extraction.

Furthermore, these two methods pinpointed the potential performance benefits when integrating waste heat recovery cycles, as it results in additional power capacity, smaller $\mathrm{CO}_{2}$-emissions, lower $\mathrm{CO}_{2}$-taxes and higher gas export. Several steam Rankine and low-temperature power cycle configurations were proposed and evaluated with respect to their investment costs and thermodynamic performance. These design setups were computed based on a multi-objective framework, and it was shown that the electricity generation potential was strongly dependent on the period at which these solutions were integrated. The integration of a steam Rankine cycle appeared to be the most promising option, as it is a mature technology which exploits efficiently the synergies between the utility and the processing plants, while being cost-competitive in comparison to a low-temperature power cycle.

The present paper supports the results of other works, which encourage the use of advanced thermodynamic analysis methods on petroleum processes. It illustrates the variations of the energy and exergy consumption trends over time, as well as the impacts of the most common field events. We suggest to (i) apply similar approaches when assessing the life performance of petroleum and energy-intensive systems, (ii) include and optimise systematically all potential improvement measures in embedded process superstructures, using relevant performance indicators, and (iii) consider such results when improving existing or designing new platforms.

\section{Acknowledgements}

The funding from the Norwegian Research Council through the Petromaks programme, within the project 2034/E30 led by Teknova is acknowledged. 


\section{References}

[1] Statistisk Sentralbyrå . Lavere klimagassutslipp i 2011. 2012. URL: www.ssb.no/emner/01/04/10/klimagassn/.

[2] Norwegian Ministry of Petroleum and Energy . Facts 2012 - The Norwegian Petroleum Sector. Tech. Rep.; Norwegian Petroleum Directorate; Oslo, Norway; 2012.

[3] Norway to set high carbon tax on oil and gas production. 2012. URL: www.offshore-technology.com/news/ newsnorway-high-carbon-tax-oil-gas.

[4] Kloster P. Energy Optimization on Offshore Installations with Emphasis on Offshore and Combined Cycle Plants. In: Proceedings of the Offshore Europe Conference. Aberdeen, United Kingdom: Society of Petroleum Engineers; 1999, p. 1-9 (Paper SPE 56964).

[5] Kloster P. Reduction of Emissions to Air Through Energy Optimisation on Offshore Installations. In: Proceedings of the SPE International Conference on Health, Safety, and the Environment in Oil and Gas Exploration and Production. Stavanger, Norway: Society of Petroleum Engineers; 2000, p. 1-7 (Paper SPE 61651).

[6] Svalheim SM. Environmental Regulations and Measures on the Norwegian Continental Shelf. In: Proceedings of the SPE International Conference on Health, Safety and Environment in Oil and Gas Exploration and Production. Kuala Lumpur, Malaysia: Society of Petroleum Engineers; 2002, p. 1-10 (Paper SPE 73982).

[7] Vanner R. Energy Use in Offshore Oil and Gas Production: Trends and Drivers for Efficiency from 1975 to 2025. PSI Working Paper; Policy Studies Institute; 2005.

[8] Linnhoff B, Smith R. Pinch principle. Mechanical Engineering 1988;110(2):70-3.

[9] Linnhoff B. Pinch technology for the synthesis of optimal heat and power systems. Journal of Energy Resources Technology, Transactions of the ASME 1989;111(3):137-47.

[10] Linnhoff B, Alanis F. Integration of a new process into an existing site. a case study in the application of pinch technology. Journal of Engineering for Gas Turbines and Power 1991;113(2):159-69.

[11] Dhole VR, Linnhoff B. Total site targets for fuel co-generation, emissions, and cooling. Computers and Chemical Engineering 1993;17:101-9.

[12] Linnhoff B, Dhole VR. Targeting for $\mathrm{CO}_{2}$ emissions for total sites. Chemical Engineering and Technology 1993;16(4):252-9.

[13] Linnhoff B, Eastwood A. Overall site optimization by pinch technology. Process Safety and Environmental Protection: Transactions of the Institution of Chemical Engineers, Part B 1997;75(Suppl):S138-44.

[14] Klemeš J, Dhole VR, Raissi K, Perry SJ, Puigjaner L. Targeting and design methodology for reduction of fuel, power and $\mathrm{CO}_{2}$ on total sites. Applied Thermal Engineering 1997;7(8-10):993-1003.

[15] Klemeš J, Friedler F, Bulatov I, Varbanov P. Sustainability in the process industry: integration and optimization. McGraw-Hill Professional; 2011.

[16] Feng X, Pu J, Yang J, Chu K. Energy recovery in petrochemical complexes through heat integration retrofit analysis. Applied Energy 2011;88:1965-82.

[17] Matsuda K, Hirochi Y, Tatsumi H, Shire T. Applying heat integration total site based pinch technology to a large industrial area in Japan to further improve performance of highly efficient process plants. Energy 2009;34(10):1687-92.

[18] Hackl R, Andersson E, Harvey S. Targeting for energy efficiency and improved energy collaboration between different companies using total site analysis (TSA). Energy 2011;36(8):4609-15.

[19] Hackl R, Harvey S. Framework methodology for increased energy efficiency and renewable feedstock integration in industrial clusters. Applied Energy 2013;112:1500-9.

[20] Moran MJ. Availability analysis: a guide to efficient energy use. 2nd ed.; New York, USA: ASME Press; 1989.

[21] Wall G. Exergy flows in industrial processes. Energy 1988;13(2):197-208.

[22] Kotas TJ. Exergy concepts for thermal plant: First of two papers on exergy techniques in thermal plant analysis. International Journal of Heat and Fluid Flow 1980;2(3):105-14.

[23] Nguyen TV, Pierobon L, Elmegaard B, Haglind F, Breuhaus P, Voldsund M. Exergetic assessment of energy systems on North Sea oil and gas platforms. Energy 2013;62:23-36.

[24] Oliveira Jr. SD, Van Hombeeck M. Exergy Analysis of Petroleum Separation Processes in Offshore Platforms. Energy Conversion and Management 1997;38(15-17):1577-84.

[25] Voldsund M, Ertesvåg IS, He W, Kjelstrup S. Exergy Analysis of the Oil and Gas Processing a Real Production Day on a North Sea Oil Platform. Energy 2013;55:716-27.

[26] Nguyen TV, Jacyno T, Breuhaus P, Voldsund M, Elmegaard B. Thermodynamic analysis of an upstream petroleum plant operated on a mature field. Energy 2014;68:454-69.

[27] Aspen Technology . Aspen Hysys 2004.2 §- User Guide. Cambridge, USA: Aspen Technology; 2004.

[28] Peng DY, Robinson DB. A New Two-Constant Equation of State. Industrial \& Engineering Chemistry Fundamentals $1976 ; 15(1): 59-64$.

[29] Twu C, Sim W, Tassone V. A versatile liquid activity model for SRK, PR and a new cubic equation-of-state TST. Fluid Phase Equilibria 2002;194-197:385-99.

[30] Manning FS, Thompson RE. Oilfield processing of petroleum: Crude oil; vol. 2. Tulsa, USA: PennWell Books; 1991.

[31] Elmegaard B, Houbak N. DNA - A General Energy System Simulation Tool. In: Amundsen J, editor. Proceedings of SIMS 2005 - 46th Conference on Simulation and Modeling. Trondheim, Norway: Tapir Academic Press; 2005 , p. 43-52.

[32] Song TW, Kim TS, Kim JH, Ro ST. Performance prediction of axial flow compressors using stage characteristics and simultaneous calculation of interstage parameters. In: Proceedings of the Institution of Mechanical Engineers; vol. 215 Part A. London, United Kingdom: Institution of Mechanical Engineers; 2001, p. 89-98.

[33] Muir DE, Saravanamuttoo HIH, Marshall DJ. Health Monitoring of Variable Geometry Gas Turbines for the Canadian Navy. ASME Journal of Engineering for Gas Turbines and Power 1989;111(2):244-50. 
[34] Spina PR. Gas Turbine performance prediction by using generalized performance curves of compressor and turbine stages. In: Proceedings of the ASME Turbo Expo 2002: Power for Land, Sea, and Air (GT2002); vol. 2. Amsterdam, The Netherlands; 2002, p. 1073-82.

[35] Templalexis I, Pilidis P, Pachidis V, Kotsiopoulos P. Development of a two-dimensional streamline curvature code. ASME Journal of Turbomachinery 2011;133(1):011003.

[36] Lieblein S. Analysis of experimental low-speed loss and stall characteristics of two-dimensional compressor blade cascades. Washington, USA: NACA RM E57A28; 1957.

[37] Saravanamuttoo HIH, Rogers GFC, Cohen H, Straznicky P. Gas Turbine Theory. Sixth ed.; Upper Saddle River, USA: Pearson Prentice Hall; 2008.

[38] Stodola A. Dampf- und Gasturbinen. Sixth ed.; Berlin, Germany: Springer; 1924.

[39] Traupel W. Thermische Turbomaschinen. Third ed.; Berlin, Germany: Springer; 1977.

[40] Ingeniøren/bøger . Pumpe Ståbi. København, Denmark: Ingeniøren A/S 2000; 2000.

[41] Faktasider. 2014. URL: factpages.npd.no/factpages/.

[42] Linnhoff B, Boland D. A user guide on process integration for the efficient use of energy. 1982.

[43] Kemp I. Pinch Analysis and Process Integration - A User Guide on Process Integration for the Efficient Use of Energy. Second ed.; Elsevier Ltd.; 2006.

[44] Maréchal F, Kalitventzeff B. Energy integration of industrial sites: Tools, methodology and application. Applied Thermal Engineering 1998;18(11):921-33.

[45] Bagajewicz M, Rodera H. Energy savings in the total site heat integration across many plants. Computers and Chemical Engineering 2000;24(2-7):1237-42.

[46] Bagajewicz M, Rodera H. Multiple Plant Heat Integration in a Total Site. AIChE Journal 2001;48(10):2255-70.

[47] Smith R. Chemical Process: Design and Integration; vol. 50. New York, USA: John Wiley \& Sons; 2005.

[48] Szargut J, Morris D, Steward F. Exergy analysis of thermal, chemical, and metallurgical processes. New York, USA: Hemisphere; 1988.

[49] Kotas TJ. The Exergy Method of Thermal Plant Analysis. Malabar, USA: Krieger Publishing; 1995.

[50] Moran MJ, Shapiro HN. Fundamentals of Engineering Thermodynamics. 6th ed.; New York, USA: John Wiley \& Sons; 2007.

[51] Bejan A, Tsatsaronis G, Moran M. Thermal Design \& Optimization. New York, USA: John Wiley \& Sons; 1996.

[52] Moran MJ. Fundamentals of exergy analysis and exergy-based thermal systems design. In: Bejan A, Mamut E, editors. Proceedings of the NATO Advanced Study Institute on Thermodynamic Optimization of Complex Energy Systems; vol. 69 of NATO Science Series. Neptun, Romania: Kluwer Academic Publishers; 1998, p. 73-92.

[53] Tsatsaronis G, Cziesla F. Encyclopedia of Physical Science and Technology; vol. 16; chap. Thermoeconomics. 3rd ed.; Academic Press; 2002, p. 659-80.

[54] Norwegian Meteorological Institute . Mean temperature - ordered report. http://eklima.met.no; 2012.

[55] Szargut J. Chemical exergies of the elements. Applied Energy 1989;32(4):269-86.

[56] Morris DR, Szargut J. Standard chemical exergy of some elements and compounds on the planet Earth. Energy $1986 ; 11(8): 733-55$.

[57] Rivero R, Rendon C, Monroy L. The Exergy of Crude Oil Mixtures and Petroleum Fractions: Calculation and Application. International Journal of Applied Thermodynamics 1999;2(3):115-23.

[58] Kotas TJ. Exergy Criteria of Performance for Thermal Plant: Second of two papers on exergy techniques in thermal plant analysis. International Journal of Heat and Fluid Flow 1980;2(4):147-63.

[59] Turton R, Bailie R, Whiting W, Shaeiwitz J, Bhattacharyya D. Analysis, Synthesis and Design of Chemical Processes. Prentice Hall International Series in the Physical and Chemical Engineering Sciences; 4th ed.; Prentice Hall; 2012.

[60] Maréchal F, Kalitventzeff B. Identification of the optimal pressure levels in steam networks using integrated combined heat and power method. Chemical Engineering Science 1997;52(17):2977-89.

[61] Rohde D, Walnum H, Andresen T, Nekså P. Heat recovery from export gas compression: Analyzing power cycles with detailed heat exchanger models. Applied Thermal Engineering 2013;60(1-2):1-6.

[62] Leyland G. Multi-objective optimisation applied to industrial energy problems. Ph.D. thesis; École Polytechnique Fédérale de Lausanne; 2002.

[63] Molyneaux A. A practical evolutionary method for the multi-objective optimisation of complex integrated energy systems including vehicle drivetrains. Ph.D. thesis; École Polytechnique Fédérale de Lausanne; 2002.

[64] Mattson C, Messac A. Pareto Frontier Based Concept Selection under Uncertainty, with Visualization. OPTE: Optimization and Engineering 2005;6(1):85-115.

[65] Rivero R. Application of the exergy concept in the petroleum refining and petrochemical industry. Energy Conversion and Management 2002;43(9-12):1199-220.

[66] Maréchal F, Kalitventzeff B. Targeting the optimal integration of steam networks: Mathematical tools and methodology. Computers and Chemical Engineering 1999;23(SUPPL. 1):S133-6.

[67] Voldsund M, Nguyen TV, Elmegaard B, Ertesvåg I, Røsjorde A, Jøssang K, et al. Exergy destruction and losses on four North Sea offshore platforms: A comparative study of the oil and gas processing plants. Energy 2014;In press:1-14. doi:10.1016/j.energy.2014.02.080.

[68] Voldsund M, Ertesvåg IS, Røsjorde A, He W, Kjelstrup S. Exergy Analysis of the Oil and Gas Separation Processes on a North Sea Oil Platform. In: Favrat D, Maréchal F, editors. Proceedings of ECOS 2010 - The 23rd International Conference on Efficiency, Cost, Optimization, Simulation and Environmental Impact of Energy Systems; vol. IV Power plants \& Industrial Processes. Lausanne, Switzerland: CreateSpace Independent Publishing Platform; 2010, p. 303-10.

[69] Voldsund M, He W, Røsjorde A, Ertesvåg IS, Kjelstrup S. Evaluation of the Oil and Gas Processing at a Real Production 
day on a North Sea Oil Platform Using Exergy Analysis. In: Desideri U, Manfrida G, Sciubba E, editors. Proceedings of ECOS 2012 - The 25th International Conference on Efficiency, Cost, Optimization, Simulation and Environmental Impact of Energy Systems; vol. II. Perugia, Italy: Firenze University Press; 2012, p. 153-66.

[70] Nord LO, Bolland O. Steam bottoming cycles offshore - challenges and possibilities. Journal of Power Technologies 2013;92(3):201-7.

[71] Nord LO, Bolland O. Design and off-design simulations of combined cycles for offshore oil and gas installations. Applied Thermal Engineering 2013;54:85-91. 